\title{
Manufacturing Processes for Permanent Magnets: Part I-Sintering and Casting
}

\author{
JUN CUI @ ${ }^{1,2,3,7}$ JOHN ORMEROD, ${ }^{1,4}$ DAVID PARKER, ${ }^{1,5}$ \\ RYAN OTT (1) ${ }^{1,2}$ ANDRIY PALASYUK, ${ }^{1,2}$ SCOTT MCCALL, $, 1,6$ \\ M. PARANS PARANTHAMAN ${ }^{1,5}$ MICHAEL S. KESLER, ${ }^{1,5}$ \\ MICHAEL A. MCGUIRE, ${ }^{1,5}$ IKENNA C. NLEBEDIM (i), ${ }^{1,2}$ \\ CHAOCHAO PAN, ${ }^{1,2,3}$ and THOMAS LOGRASSO ${ }^{1,2,3}$
}

1.-Critical Materials Institute, Ames, IA 50011, USA. 2.-Ames Laboratory, Ames, IA 50011, USA. 3.-Material Science and Engineering Department, Iowa State University, Ames, IA 50011, USA. 4.-JOC LLC, Loudon, TN 37774, USA. 5.-Oak Ridge National Laboratory, Oak Ridge, TN 37831, USA. 6.-Lawrence Livermore National Laboratory, Livermore, CA 94550, USA. 7.—e-mail: cuijun@ameslab.gov

\begin{abstract}
Permanent magnets (PMs) produce magnetic fields and maintain the field even in the presence of an opposing magnetic field. Electrical machines using permanent magnets are more efficient than those without. Currently, all known strong magnets contain rare earth (RE) elements, and they are core components of a wide range of applications including electric vehicles and wind turbines. RE elements such as Nd and Dy have become critical materials due to the growing demand and constrained supply. Improving the manufacturing process is effective in mitigating the $\mathrm{RE}$ criticality issue by reducing waste and improving parts consistency. In this article, the state of the industry for PM is reviewed in detail considering both the technical and economic drivers. The importance of $\mathrm{RE}$ elements is discussed along with their economic importance to green energy. The conventional sintering and casting manufacturing processes for commercial magnets, including $\mathrm{Nd}-\mathrm{Fe}-\mathrm{B}, \mathrm{Sm}-\mathrm{Co}$, Alnico, and ferrite, are described in detail.
\end{abstract}

\section{INTRODUCTION}

"A magnet is fundamentally an energy-storage device. This energy is put into it when it is first magnetized, and it remains in the magnet indefinitely, if properly made and properly handled". Unlike in a battery, a magnet's energy is not drained away and always available for use. This is because a magnet does not do a net work on its surroundings; instead, a magnet lends its energy to attract or repel other magnetic objects, thereby assisting in converting between electrical and mechanical energy. A permanent magnet is unique in that once produced, it provides a magnetic flux with no energy input, hence zero operating cost. By contrast, electromagnets require a continuous electrical current to generate a magnetic field and

(Received May 27, 2021; accepted January 3, 2022;

published online February 2, 2022) operate. Permanent magnets today are used in a wide range of motors, wind turbines, electronics, and medical devices. Their special technological importance derives from the ability to act without contact, by either attraction or repulsion, interact with and generate a force on a charged particle or a conductor carrying an electrical current. Figure 1 shows the major device types using permanent magnets.

\section{Key Figures of Merit}

Magnetization is the sum of the electron spin and orbital moments per unit volume in a material, and in ferromagnets these moments align over long ranges to provide values of magnetization millions of times greater than most materials. The distinguishing characteristic of a PM is that it can produce and maintain magnetic fields even in the presence of an opposing external magnetic field. But if the opposing field's magnitude is strong enough, 


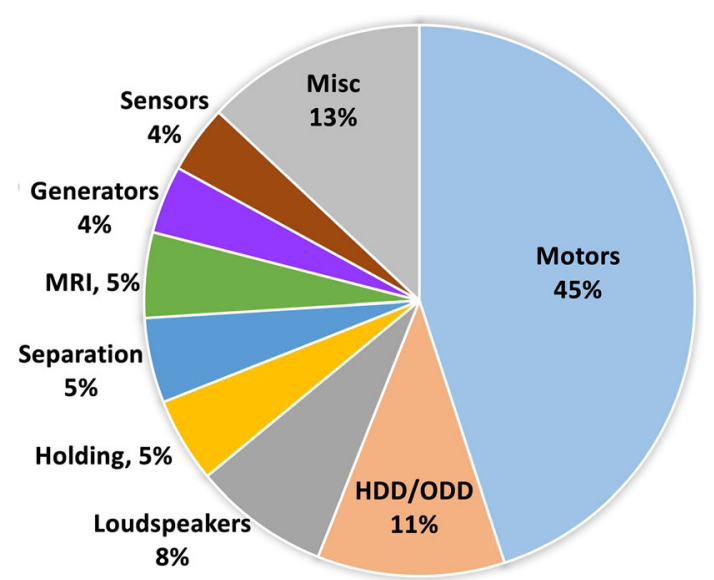

Fig. 1. Applications of permanent magnets by market (\$) share in 2019. Adapted from Ormerod ${ }^{2}$.

the magnetic domains within the permanent magnet will follow the opposing field, causing the PM to be demagnetized. This maximum opposite field is termed coercivity, $H_{\mathrm{c}}$. While $H_{\mathrm{c}}$ describes the ability of a permanent magnet to resist demagnetizing fields, magnetic flux density $B$ is related to the force generated with the magnet. It is the sum of $M$ and $H$, where $M$ is the magnetization of the magnet and $H$ is the external field in the magnet due to its permeability, $\mu$. When $H$ is zero, the remaining magnetic flux density, $B_{\mathrm{r}}$, is the same as the remanent magnetization, $M_{\mathrm{r}}$, of the magnet. When $H$ exceeds $H_{\mathrm{c}}$, the $M$ will follow the $H$ direction. If $H$ is high enough, the magnetization will be saturated, reaching saturation magnetization, $M_{\mathrm{s}} . H_{\mathrm{c}}$ is sensitive to extrinsic microstructures and intrinsic magnetocrystalline anisotropy (MAE). MAE is typically written in terms of either an anisotropy field, $H_{\mathrm{a}}$, or a first anisotropy constant, $K_{1} . H_{\mathrm{a}}$ and $K_{1}$ are related, to the lowest order, by $\mu_{0} H_{\mathrm{a}}=2 \mu_{0} K_{1} / M_{\mathrm{s}}$, where $\mu_{0}$ is the vacuum permeability of free space $4 \pi \times 10^{-7} \mathrm{~Wb} /(\mathrm{Am})$. While the units of electromagnetism have been a rarely penetrable thicket since the days of Maxwell, a useful rule to remember is that for a $1 \mathrm{MJ} / \mathrm{m}^{3} K_{1}$ and $796 \mathrm{kA} / \mathrm{m}(10 \mathrm{kG}) M_{\mathrm{s}}$, the anisotropy field $H_{\mathrm{a}}$ is $2000 \mathrm{kA} / \mathrm{m}(25 \mathrm{kOe})$. Both $H_{\mathrm{a}}$ and $M_{\mathrm{s}}$ are sensitive to temperature. For most magnets, $H_{\mathrm{a}}$ decays faster than $M_{\mathrm{S}}$ with increasing temperature. At the Curie point, $T_{\mathrm{c}}$, a magnet will completely lose its permanent magnetic properties. To compare these values to electromagnets, a single turn coil with a $1 \mathrm{~cm}$ diameter requires $\sim 400 \mathrm{~mA}$ to generate a magnetic field of $40 \mathrm{~A} / \mathrm{m}(0.5 \mathrm{G})$, which is the Earth's magnetic field at the surface. Permanent magnets routinely generate fields several thousand times stronger.

The energy of the magnetic field outside the magnet is proportional to the product of $B$ and $H$. This is represented as any point in the second quadrant of the demagnetization curve shown in Fig. 2. The volume of a magnet required to produce

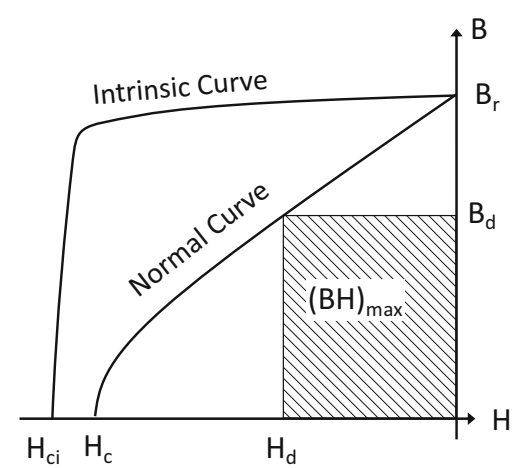

Fig. 2. A typical demagnetization curve of a permanent magnet. The intrinsic curve represents the magnetization, $M$, while the normal curve represents $B=\mu_{\mathrm{o}}(H+M)$. $(B H)_{\max }$ is the point where $\mathrm{BH}$ is largest and provides a measure of the energy accessible from the magnet to do work.

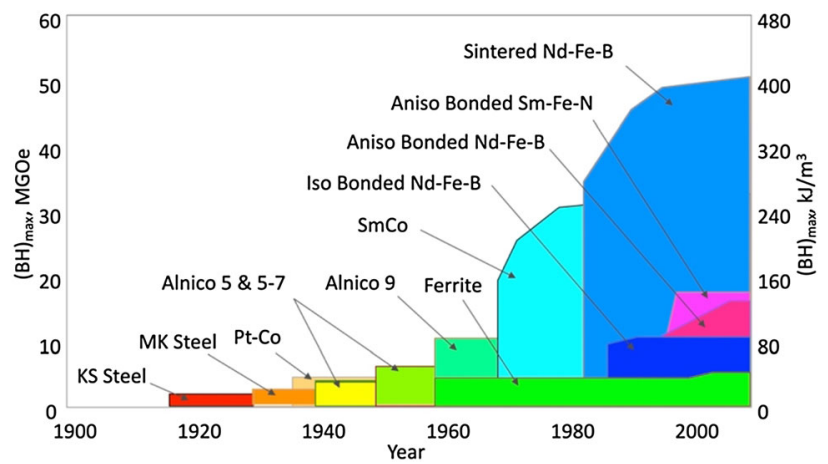

Fig. 3. Historical trend of the improvement in the maximum energy product for commercially produced permanent magnets. Adapted from M. J. Kramer. ${ }^{10}$

a given field in a gap is minimum when the product of $B H$ is maximum, i.e., $(B H)_{\max }$. The higher the $(B H)_{\max }$, the smaller the magnet volume needed to generate a given flux density. One can also conceptualize $(B H)_{\max }$ as a value of the potential magnetostatic energy per unit volume of the magnet material. The unit of $(B H)_{\max }$ is Mega Gauss Oersteds (MGOe, or $\mathrm{kJ} / \mathrm{m}^{3}$ in SI units where $\left.1 \mathrm{MGOe} \sim 8 \mathrm{~kJ} / \mathrm{m}^{3}\right)$. In the permanent magnet industry, $(B H)_{\max }$ is the most frequently used indicator of permanent magnets' performance.

\section{History of Permanent Magnet Development}

Several comprehensive reviews exist which extensively cover the development of rare earth (RE) magnets and the factors determining their coercivity. ${ }^{3-9}$ Figure 3 shows the historical development and commercialization of permanent magnets based on their $(B H)_{\max } \cdot{ }^{10}$ It is noteworthy that the main discoveries of new commercial hard magnetic materials and the advancement in $(B H)_{\max }$ have occurred exclusively during the twentieth century. No major new magnetic material has been introduced since $\mathrm{Nd}-\mathrm{Fe}-\mathrm{B}$ in the early $1980 \mathrm{~s}$; in fact, it is now more than 38 years since the announcement of Nd-Fe-B 
magnets at the 29th MMM Conference held in Pittsburgh, PA, in November 1983.

The dramatic improvement in magnetic performance began with magnet steels in the early $1900 \mathrm{~s}$, where $H_{\mathrm{c}}$ was developed through a strain-induced mechanism. Alnico magnets with $H_{\mathrm{c}}$ based on shape anisotropy (alnico 9) were commercialized in the early 1960s. However, both industrial and academic researchers realized that future major advances in permanent magnet materials would require higher $H_{\mathrm{c}}$ and therefore needed to shift emphasis from shape anisotropy to MAE. So, in the 1960s the search began for uniaxial compounds that combine high $M_{\mathrm{s}}$ with high MAE. In terms of new compounds, the RE intermetallics were of particular interest because: (1) Several RE elements display magnetic ordering and large magnetic moments albeit at low temperatures. (2) REs tend to form intermetallic compounds in the binary systems with $3 \mathrm{~d}$ transition metals (TM). (3) It is possible to form a strong coupling of the RE moment with the TM moment. This led to the breakthrough discovery by Strnat and his team at the University of Dayton in 1966 , where they measured $H_{\mathrm{a}}$ of $>11,141 \mathrm{kA} / \mathrm{m}$ $(140 \mathrm{kOe})$ on single crystal samples of $\mathrm{YCo}_{5} .{ }^{11}$

To be possible candidates for a permanent magnet material, the compound must combine the basic attributes of high $M_{\mathrm{s}}, T_{\mathrm{c}}$, and MAE. When these criteria are mutually considered, then the search for possible RE-TM intermetallics narrowed to $\mathrm{RCo}_{5}$ and $\mathrm{R}_{2} \mathrm{Co}_{17}$ compounds, which ultimately led to the development and commercialization of rare earth permanent magnets (REPMs) based on the binary $\mathrm{SmCo}_{5}$ and multicomponent $\mathrm{Sm}_{2} \mathrm{Co}_{17}$ systems. Structurally, these two systems are very similar, with the major distinction being that in the $2-17$ system, every third Sm atom is replaced by a Co-Co dimer.

The search for a RE-iron based permanent magnet began in the late 1970s following the cobalt raw material supply crisis. This eventually led to the simultaneous development of magnets based on the $\mathrm{Nd}_{2} \mathrm{Fe}_{14} \mathrm{~B}$ tetragonal compound by both Sumitomo Special Metals (SSM) in Japan and General Motors (GM) in the US in the early $1980 \mathrm{~s} .{ }^{12}$ SSM was later to form a joint venture with Hitachi and eventually merged as Hitachi Metals Ltd. in 2007. GM spun off the Nd-Fe-B magnet business as Magnequench, today part of Neo Performance Materials. The Hitachi production method is based on powder metallurgical processing, and the Magnequench process uses melt spinning. However, both types of magnets are based on the same $\mathrm{Nd}_{2} \mathrm{Fe}_{14} \mathrm{~B}$ tetragonal compound, but have vastly different microstructures and use different processing routes. ${ }^{12}$

\section{Criteria for Permanent Magnet Development}

The first criterion, rather practically based, is $H_{\mathrm{a}} \geq 3 M_{\mathrm{s}}$. Decades of "hard" permanent magnet experience have shown that to attain large energy products, one usually needs an $H_{\mathrm{c}}$ at least as large as $M_{\mathrm{s}}$. This generally allows magnet hysteresis loops with a sufficient 'safety margin' to avoid demagnetization in actual application usage (noting that, as Coey has written, $H_{\mathrm{c}}>M_{\mathrm{s}} / 2$ is really the bare minimum to attain the maximum energy product). Since the $H_{\mathrm{c}}$ is virtually never more than a third of $H_{\mathrm{a}}$, one needs at a minimum $H_{\mathrm{a}} \geq 3 M_{\mathrm{s}}$. Strictly speaking, the well-known criterion $k=\left(K_{1} /\right.$ $\left.\mu_{0} M_{\mathrm{s}}^{2}\right)^{1 / 2}>1$ reduces to $H_{\mathrm{a}}>2 M_{\mathrm{s}}$, but we adopt here a more conservative condition. ${ }^{13}$ Ferrites were the first material to meet this criterion, followed in later decades by the $\mathrm{RCo}_{5}$ family, including $\mathrm{SmCo}_{5}$ and $\mathrm{CeCo}_{5}$, and still later by $\mathrm{Nd}_{2} \mathrm{Fe}_{14} \mathrm{~B}$. As Coey has written, ${ }^{14}$ the field of permanent magnets underwent a paradigm shift with the serendipitous discovery of ferrite magnets in 1950, as these magnets broke the "shape barrier"-i.e., removed the need to be manufactured into technologically awkward shapes such as the "bar magnet." The reason these magnets were able to do this is intimately related to this criterion $H_{\mathrm{a}} \geq 3 M_{\mathrm{s}}$.

The second criterion is $T_{\mathrm{c}} \geq 227^{\circ} \mathrm{C}$. A magnet must retain its magnetic properties to fulfill its desired function, and the key magnetic properties, magnetization and coercivity, both begin to drop sharply above about $80 \%$ of $T_{\mathrm{c}}$. How far above room temperature is an open question, since this depends on the relevant application, but a reasonable rule of thumb obeyed by all useful magnets is $T_{\mathrm{c}} \geq 227^{\circ} \mathrm{C}$. One relevant point in this light is that certain properties, such as coercivity, often decrease much more quickly with increasing temperature than magnetization, so that for many applications $227^{\circ} \mathrm{C}$ is an optimistic lower bound. For example, substantial measures, such as usage of the very costly Dy, are often taken to retain high temperature coercivity in $\mathrm{Nd}_{2} \mathrm{Fe}_{14} \mathrm{~B}$, despite its comparatively high $T_{\mathrm{c}}$ of $312^{\circ} \mathrm{C}$.

The third criterion is on the magnetization, but somewhat less precise. While a higher $\mathrm{M}$ is desired, a magnet with lower $M$ could be successfully used too. One may say a few things based on the substantial difference in room-temperature magnetization between hard ferrite $[\sim 318 \mathrm{kA} / \mathrm{m}(4 \mathrm{kG})]$ and $\mathrm{Nd}_{2} \mathrm{Fe}_{14} \mathrm{~B}[\sim 1273 \mathrm{kA} / \mathrm{m}(16 \mathrm{kG})]$. These are the two most popular magnets by total sales worldwide. Now, the energy product is limited to be no more than $M_{\mathrm{s}}^{2} / 4,509 \mathrm{~kJ} / \mathrm{m}^{3}$ (or 64 MGOe) for $\mathrm{Nd}_{2} \mathrm{Fe}_{14} \mathrm{~B}$, with more typically $\leq 80 \%$ of this value achieved even after years of effort.

Table I lists an average $(B H)_{\max }$ for each material type, the average price/kg, the price/volume using the densities of the materials and finally a price/ performance ratio by dividing the average $(B H)_{\max }$ by the price/volume. It shows hard ferrite has the lowest price/performance ratio, reflecting its relatively large market share despite its inferior properties compared to $\mathrm{Nd}-\mathrm{Fe}-\mathrm{B} .^{2}$

If this price/performance metric is an indicator of overall market success, then the $\$ / \mathrm{m}^{3}$ of the new 
Table I. Optimum price performance metric for permanent magnets (W. Benecki, S. Constantinides, S. Trout, J. Jia and K. Liu, personal communications, 2020)

\begin{tabular}{|c|c|c|c|c|c|}
\hline Material & $\begin{array}{c}(\mathbf{B H})_{\max }, \\
\mathbf{k J} / \mathbf{m}^{\mathbf{3}}(\mathbf{M G O e})\end{array}$ & $\begin{array}{c}\text { Average } \\
\text { Price, } \$ / \mathbf{k g}\end{array}$ & $\begin{array}{c}\text { Density, } \\
\text { kg/m }\end{array}$ & $\begin{array}{c}\text { Average } \\
\text { price, } \$ / \mathbf{m}^{3}\end{array}$ & $\begin{array}{c}\text { Price/performance, } \\
\$ / \mathbf{k J}\left(\$ / \mathbf{m}^{3} / \mathbf{M G O e}\right)\end{array}$ \\
\hline Nd-Fe-B & $358(45)$ & 70 & 7500 & 525,500 & $1468(11,678)$ \\
\hline Ferrite & $28(3.5)$ & 6.4 & 5000 & 32,000 & $1142(9142)$ \\
\hline Bonded Nd-Fe-B & $64(8)$ & 91 & 5100 & 464,100 & $7252(58,012)$ \\
\hline Sm-Co & $199(25)$ & 95 & 8400 & 798,000 & $4010(31,920)$ \\
\hline Alnico & $56(7)$ & 56 & 7300 & 408,800 & $7300(58,400)$ \\
\hline
\end{tabular}

magnet materials will need to be such that its price/ performance ratio is $<12$. This may be the most difficult challenge to overcome for a new mass market magnet material. Figure 4 shows a plot of the $\$ / \mathrm{m}^{3}$ versus average $(B H)_{\max }$ of the different material types from the table above and a line with a slope of 12 representing the division between what are the niche (Alnico, Sm-Co, bonded $\mathrm{Nd}-\mathrm{Fe}-\mathrm{B}$ ) and mass (hard ferrite, Nd-Fe-B) market materials.

\section{Permanent Magnet Market}

The permanent magnet market is relatively small at $\$ 21$ billion (2020) compared to other industrial markets. However, permanent magnets are critical and enabling for many high-value downstream products that represent many 100 s of billion dollars of market value.

The estimate of the global permanent magnet market for 2018 and 2020 and projected market for 2030 and 2040 are summarized in Table II. ${ }^{2}$

The magnet market is dominated by Nd-Fe-B and hard ferrite magnets. Over $90 \%$ of all permanent magnets produced and used are of these two magnet material types, quite different in terms of magnetic performance and cost. On a weight basis, hard ferrite magnets dominate the production of all permanent magnet types, representing $>80 \%$ of total global permanent magnet production.

The automotive sector is by far the largest user of magnets. Traditionally, this was dominated by hard ferrite magnets; however, this is changing. This is a trend that began a few years ago but is now accelerating rapidly, and automotive will become a major consumer of $\mathrm{RE}$ magnets. The automotive industry uses magnets in power seats, power windows, fuel pumps, oil pumps, starters, alternators, cooling fans, air conditioning, power steering, windshield wipers, electrical turbochargers, etc. In terms of future growth in the permanent magnet market, the single largest driver will be the traction drives for electrical vehicles (EVs) and hybrid EVs (HEVs). Permanent magnet motors are the lightest, most power dense, and most efficient type of motor used in EVs. Although the bill of materials for a REPM motor is approximately $20 \%$ higher than that of a comparable induction motor, the REPM motor is $10-15 \%$ more efficient than the induction motor. ${ }^{15,16}$

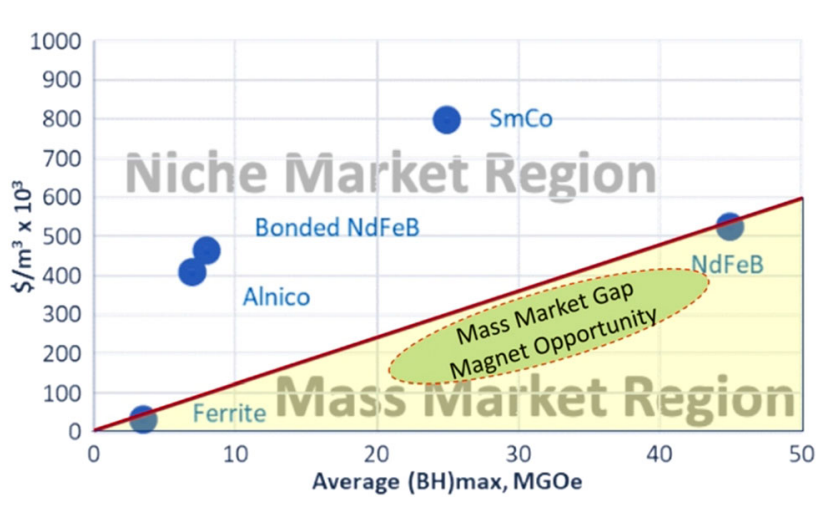

Fig. 4. Niche and mass market materials.

A ferrite-based PM motor could be as efficient as an REPM motor. However, with only one third of the remnant flux density and one fifth of the coercivity of the Nd-Fe-B magnets, ferrite magnets make it difficult to design a motor with high torque and power density. In 2017, the US Department of Energy Vehicle Technologies Office announced 50 $\mathrm{kW} / \mathrm{L}$ as the 2025 target for the traction motor powder density. ${ }^{17}$ This is a dramatic push from the previous 2020 target of $5.7 \mathrm{~kW} / \mathrm{L}$. Even with the powerful REPM, such an aggressive target is extremely difficult to achieve. Several studies are forecasting EV/HEV production will reach $>60$ million units annually by $2030 .^{18-20}$ If $2 \mathrm{~kg}$ of NdFe-B-based magnet material is used in each vehicle, then $>120,000$ tons will be required for this one application in 2030 .

Other future major market growth drivers include electric bicycles, drones, wind/tidal energy generators, and robotics. Tables I and II shows the growth projections of the major magnet material in 2030 and 2040.

\section{Supply Risk and Mitigation Strategies}

The 2030 forecast for Nd-Fe-B demand is concerning in terms of raw materials, separation, and metal reduction availability. This will require pursuing strategies such as those outlined in the DOE's Critical Materials Strategy. ${ }^{21}$ First, diversified global supply chains are essential. To manage supply risk, multiple sources of materials are 
Table II. Estimated permanent magnet market 2018-2020 and projected market 2030-2040.

\begin{tabular}{|c|c|c|c|c|c|c|}
\hline \multirow[b]{2}{*}{ Material } & \multicolumn{2}{|c|}{2018} & \multicolumn{2}{|c|}{2020} & \multirow{2}{*}{$\frac{2030}{\text { Weight (tons) }}$} & \multirow{2}{*}{$\frac{2040}{\text { Weight (tons) }}$} \\
\hline & Weight (tons) & Value (\$M) & Weight (tons) & Value (\$M) & & \\
\hline Nd-Fe-B & 160,000 & 11,200 & 190,000 & 12,500 & 450,000 & 600,000 \\
\hline Ferrite & 830,000 & 5800 & 900,000 & 6500 & 950,000 & $1,000,000$ \\
\hline Bonded NdFeB & 11,000 & 1000 & 12,000 & 1100 & 14,000 & 18,000 \\
\hline $\mathrm{Sm}-\mathrm{Co}$ & 4200 & 400 & 4400 & 450 & 4600 & 5000 \\
\hline Alnico & 6300 & 350 & 6750 & 400 & 6750 & 7000 \\
\hline Other & 2000 & 150 & 2200 & 175 & 2500 & 3000 \\
\hline Total & & $\$ 19 B$ & & $\$ 21 B$ & & \\
\hline
\end{tabular}

required. This means taking steps to facilitate extraction, processing, and manufacturing in the USA, as well as encouraging other nations to expedite alternative supplies. In all cases, extraction, separation, and processing should be done in an environmentally sound manner. Second, alternatives must be developed. Research leading to material and technology substitutes will improve flexibility and help meet the material needs of the clean energy economy. Third, recycling, reuse and more efficient use could significantly lower world demand for newly extracted materials. Research into recycling processes coupled with well-designed policies will help make recycling economically viable over time.

Current designs for $\mathrm{EV} / \mathrm{HEV}$ traction motors require $\mathrm{Nd}-\mathrm{Fe}-\mathrm{B}$ grades capable of resisting high demagnetizing fields at temperature $>180^{\circ} \mathrm{C}$. The standard commercial approach requires significant amounts of Dy to increase high-temperature coercivity. Figure 5 shows the amount of Dy needed for the Nd-Fe-B magnet to exhibit the rated coercivity at temperatures specific to several applications. Based on these projections, $>10,000$ tons of HREE (Dy or $\mathrm{Tb}$ ) will be required in 2030 using current bulk alloying manufacturing methods. The global rare earth production was about 240,000 tons in 2020 , and Dy production was only about $1 \%$ of the total or about 2400 tons. $^{22}$ It appears that a severe supply shortage of $\mathrm{Dy} / \mathrm{Tb}$ will occur by the middle of this decade without substantial increases in supply. However, with improvements to soft magnetic materials, thermal conductivity of electrically isolating materials, and motor cooling methods, the demand on REPM's high temperature properties may be reduced to a certain extent.

\section{COMMON MAGNET FABRICATION PROCESSES: SINTERING AND CASTING}

\section{Sm-Co}

Almost all fully dense REPMs are produced using the same basic powder metallurgical processes. However, there are some detailed differences between $\mathrm{SmCo}_{5}, \mathrm{Sm}_{2} \mathrm{Co}_{17}$, and $\mathrm{Nd}_{2} \mathrm{Fe}_{14} \mathrm{~B}$ magnets,

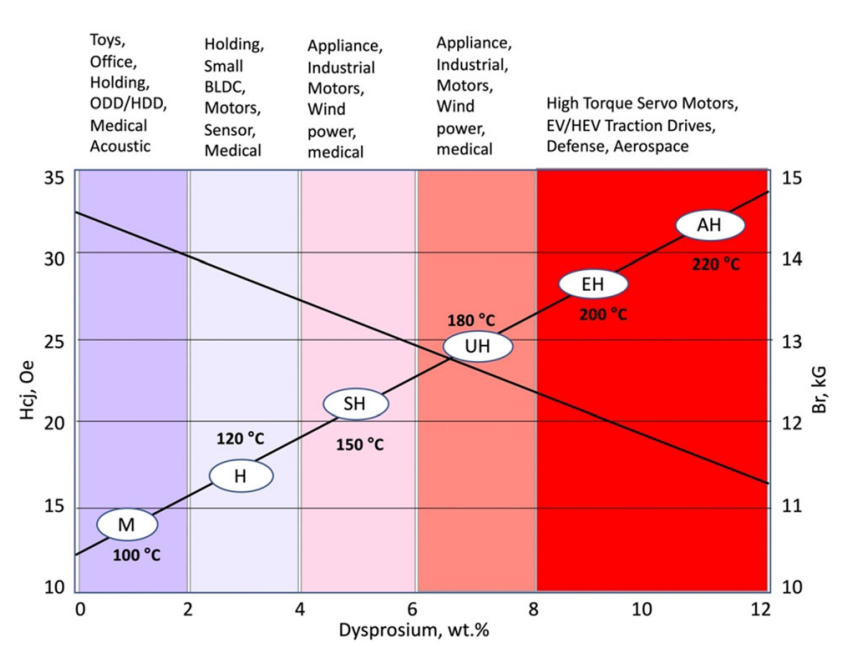

Fig. 5. Effect of Dy on Nd-Fe-B's coercivity and the operating temperature for various applications. Adapted from M. J. Kramer. ${ }^{10}$

and each manufacturer has its own customized variant. The high reactivity of the RE elements and their alloys and the critical dependence of the magnetic properties on the chemical composition require effective suppressions of contamination during the alloy preparation and subsequent powder metallurgical processing. In particular, oxidation of the RE components by air and moisture must be kept to a minimum through all fine-powder handling, sintering, and heat treatment stages.

The basic process steps for the Sm-Co-based magnets are shown in Fig. $6 .^{23}$ The general process consists of alloy preparation, powder production, particle alignment and pressing, sintering and heat treatment, machining, and finally magnetizing.

\section{Alloy Preparation}

RE-3d transition metal alloys can be produced on an industrial scale by vacuum induction melting. Inert gas is back filled to the vacuumed chamber before melting. It is common for Sm-Co alloys to be ingot cast. 


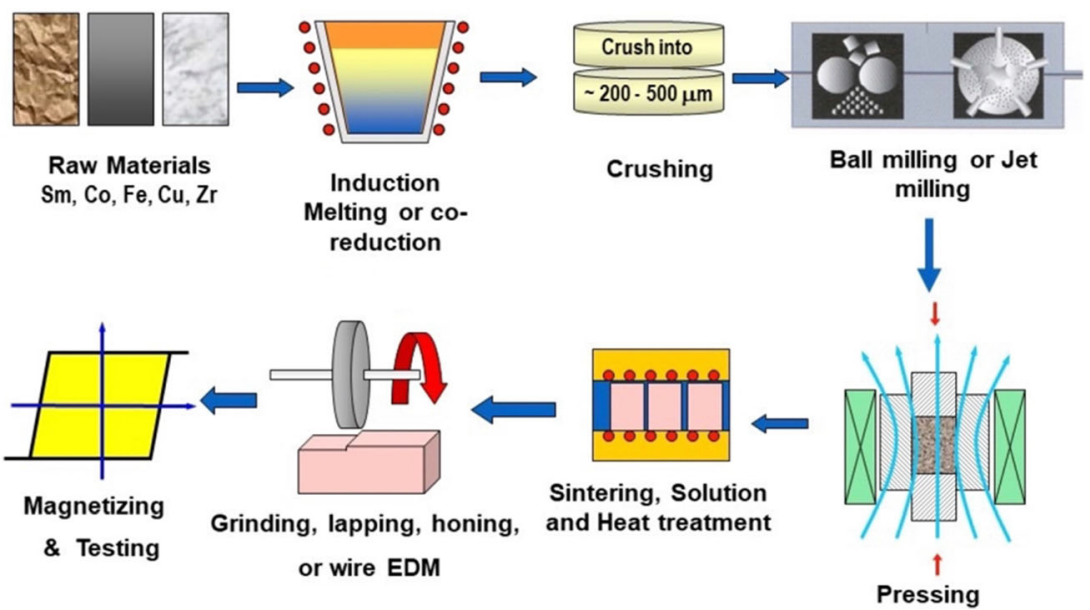

Fig. 6. Basic process steps for the Sm-Co based magnets. Reprinted with permission by Dr. Jinfang Liu. ${ }^{23}$

\section{Powder Production}

Depending on the method used to prepare the alloy, the material may require a size reduction stage prior to final milling. For example, after vacuum melting and casting, the Sm-Co alloy is in the form of chill cast lumps. They are typically crushed, under a nitrogen atmosphere in a high energy hammer mill, to a particle size range of $<500 \mu \mathrm{m}$. The objective of milling the REPM alloys is to produce a narrow size distribution of singlecrystal particles, i.e., individual particles containing no grain boundaries and therefore only one preferred axis of magnetization. In addition, sufficient particle surface area must be present for high sinter reactivity. For single-phase magnets, where the coercivity is controlled by domain nucleation and wall pinning at grain boundaries, the particle size and surface condition play a critical role in determining the coercivity of the sintered magnet. The critical parameters to be controlled during milling are particle size, particle size distribution, defects in crystal structure, and oxidation. The milling process can be carried out by either ball milling in an organic liquid under an inert gas, e.g., attritor milling in cyclohexane, or by jet milling, a dry milling process in which the attrition action is mainly due to high-velocity particle-particle collisions.

\section{Particle Alignment and Pressing}

To obtain a compact with maximum magnetization, the powder particles are aligned and pressed such that the easy axis of magnetization of the powders are parallel. The powder compaction is performed by die pressing or isostatic pressing. In the first method, the aligning magnetic field is set up in the cavity of a non-magnetic die with the field direction applied either in the direction of pressing or orthogonal to it. ln the large-scale production,

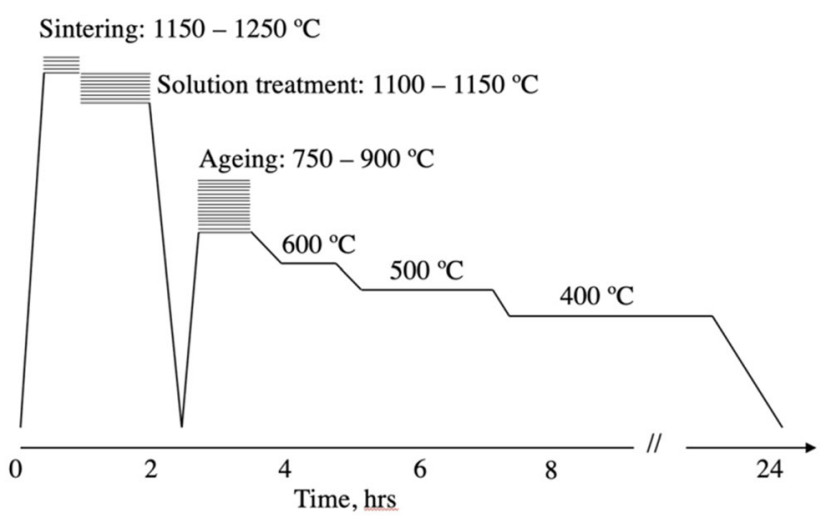

Fig. 7. Typical temperature profile used to heat treat $\mathrm{Sm}_{2} \mathrm{Co}_{17}$-type permanent magnets.

multi-impression tooling is generally used. A high homogeneous field is required to produce a high level of uniform alignment. The applied field can be static or some combination of static and pulsed. The degree of alignment is influenced by particle shape, particle size distribution, magnitude of aligning field, and pressing pressure. The pressing pressure should be sufficient to give the powder compact enough mechanical strength to withstand handling but not high enough to cause particle misorientation. Isostatic pressing is normally carried out on powders pre-aligned in a pulsed magnetic field of a level three or four times that used in uniaxial die pressing. This improves the degree of particle alignment, which is then maintained during isostatic pressing, and results in higher $B_{\mathrm{r}}$ and $(B H)_{\max }$ values than for die-pressed pieces.

\section{Sintering and Heat Treatment}

The sintering of REPM is carried out in inert gas atmospheres, reducing atmospheres or under vacuum. The sintering treatment should result in a 
magnet with a high density and no appreciable grain growth to retain a high coercivity. A constant and well-defined sintering temperature is necessary to ensure the magnet has no open porosity which could lead to oxidation and aging during use. This requires the density to be $>95 \%$ of theoretical density. An additional heat treatment is necessary for all types of REPMs to develop the optimum coercivity and loop shape properties. Figure 7 shows the typical multistep heat treatment for a multicomponent $\mathrm{Sm}_{2} \mathrm{Co}_{17}$-type magnet to develop optimum magnetic properties. ${ }^{24}$

\section{Machining}

During the sintering operation, the pressed product volume reduces to the final magnet body. This shrinkage depends upon production factors and the final magnet shape and size. This results in some variation in magnet size, and therefore a machining operation is necessary. REPMs are in general hard and brittle, although Nd-Fe-B magnets are tougher and less susceptible to breakage and chipping than Sm-Co magnets. Magnetic chucks are therefore not used to hold pieces down directly. Small series items are fastened by special adhesives to steel backing plates and then ground on conventional grinding machines fitted with either silicon carbide or diamond grinding wheels. Large series production is ground on double disc machines where the pieces are moved between two grinding wheels set the required distance apart. Small blocks can be slit using diamond impregnated wheels. Machined surfaces are required to give the necessary magnetic contact with the associated components in the final assembly.

\section{Magnetization}

Since most REPMs combine relative recoil permeabilities close to unity (i.e., steep demagnetization curve) and high coercivity, they may be magnetized prior to assembly without flux loss. However, because of the difficulty of handling magnetized and brittle material, it is common for the user to carry out magnetization during the system assembly. The magnetizing force required to saturate a magnet depends on the coercivity of the magnetic material and, to a lesser extent, physical characteristics of the magnet and components to which it may be fastened during the magnetizing. The general rule is that to saturate a magnet, one must apply a peak field of between 1.5 and 2.5 times the intrinsic coercivity. For example, an $H_{\mathrm{ci}}$ of $1592 \mathrm{kA} / \mathrm{m}(20 \mathrm{kOe})$ will require at least $3183 \mathrm{kA} /$ $\mathrm{m}(40 \mathrm{kOe})$ to saturate. In the case of magnets attached to conductive fixtures, eddy currents are established in the material that set up a reverse magnetic field during the extremely short magnetizing pulse. This prevents the magnetizing flux from fully penetrating the conductor, perhaps even the magnet, and reduces the field the magnet experiences and sometimes also the direction of the flux in the magnet. In these cases, it is necessary for the equipment manufacturer to adjust the LC (inductance capacitance ratio) of the magnetizing circuit to extend the magnetizing pulse width. However, an extended pulse generates more heat in the capacitor bank that provides the pulse current, which slows the production magnetizing rate and shortens the capacitor's life, so a careful compromise must be reached.

\section{Testing and Classifying}

Full second quadrant demagnetization curves are required from a representative sample from each batch of magnets. A batch is typically defined as the load from the final heat treatment furnace. A larger sample should be magnetized and then measured using a Helmholtz coil and flux meter against an agreed standard magnet. It may also be necessary to measure the side-to-side flux using a Hall probe and Gauss meter. Depending on the variation of magnetic properties (both batch to batch and within a batch), it may be necessary to classify the magnets within specific flux bands.

\section{Nd-Fe-B}

\section{Alloying and Strip Casting}

The magnet alloy's target composition and proper microstructure are established through vacuum induction melting and casting, using either vacuum or argon to reduce oxygen contamination. The ingredients are the $\mathrm{RE}$ metals, along with iron, cobalt, ferro-boron ( $\mathrm{Fe}-\mathrm{B})$, and reclaimed alloy material. Figure 8 shows the outline for a typical $\mathrm{Nd}-\mathrm{Fe}-\mathrm{B}$ magnet production process. ${ }^{2}$

The microstructure of the starting alloy used for producing sintered magnets is critically important. ${ }^{12}$ The major challenge is that the $\mathrm{Nd}_{2} \mathrm{Fe}_{14} \mathrm{~B}$ intermetallic compound forms by a peritectic reaction, where a liquid and solid phase reacts to form a second phase. In this instance, $\mathrm{Nd}_{2} \mathrm{Fe}_{14} \mathrm{~B}$ forms by peritectic reaction from a liquid plus $\gamma$-Fe. At normal cooling rates, this reaction does not go to completion, and the cast alloy is found to contain a mixture of the $\mathrm{Nd}_{2} \mathrm{Fe}_{14} \mathrm{~B}, \mathrm{NdFe}_{4} \mathrm{~B}_{4}$, and $\alpha-\mathrm{Fe}$ [the (FCC) $\gamma-\mathrm{Fe}$ converts to (BCC) $\alpha-\mathrm{Fe}$ at $910^{\circ} \mathrm{C}$ ]. The presence of the $\alpha-\mathrm{Fe}$ is a problem for sintered magnet producers because it is a comparatively ductile phase compared to the brittle $\mathrm{Nd}_{2} \mathrm{Fe}_{14} \mathrm{~B}$ alloy and makes crushing and grinding of the ingot into a powder much more difficult. Another serious problem for sintered $\mathrm{Nd}$ magnets is that the $\alpha$-Fe is magnetically soft and results in a reduction in magnetic performance (kinked B-H loop) in the finished magnets. Elimination of secondary phases can be accomplished by a lengthy high-temperature annealing during which the secondary phases react together to form the desired $\mathrm{Nd}_{2} \mathrm{Fe}_{14} \mathrm{~B}$ intermetallic phase. However, this annealing or homogenization process is slow and costly. 


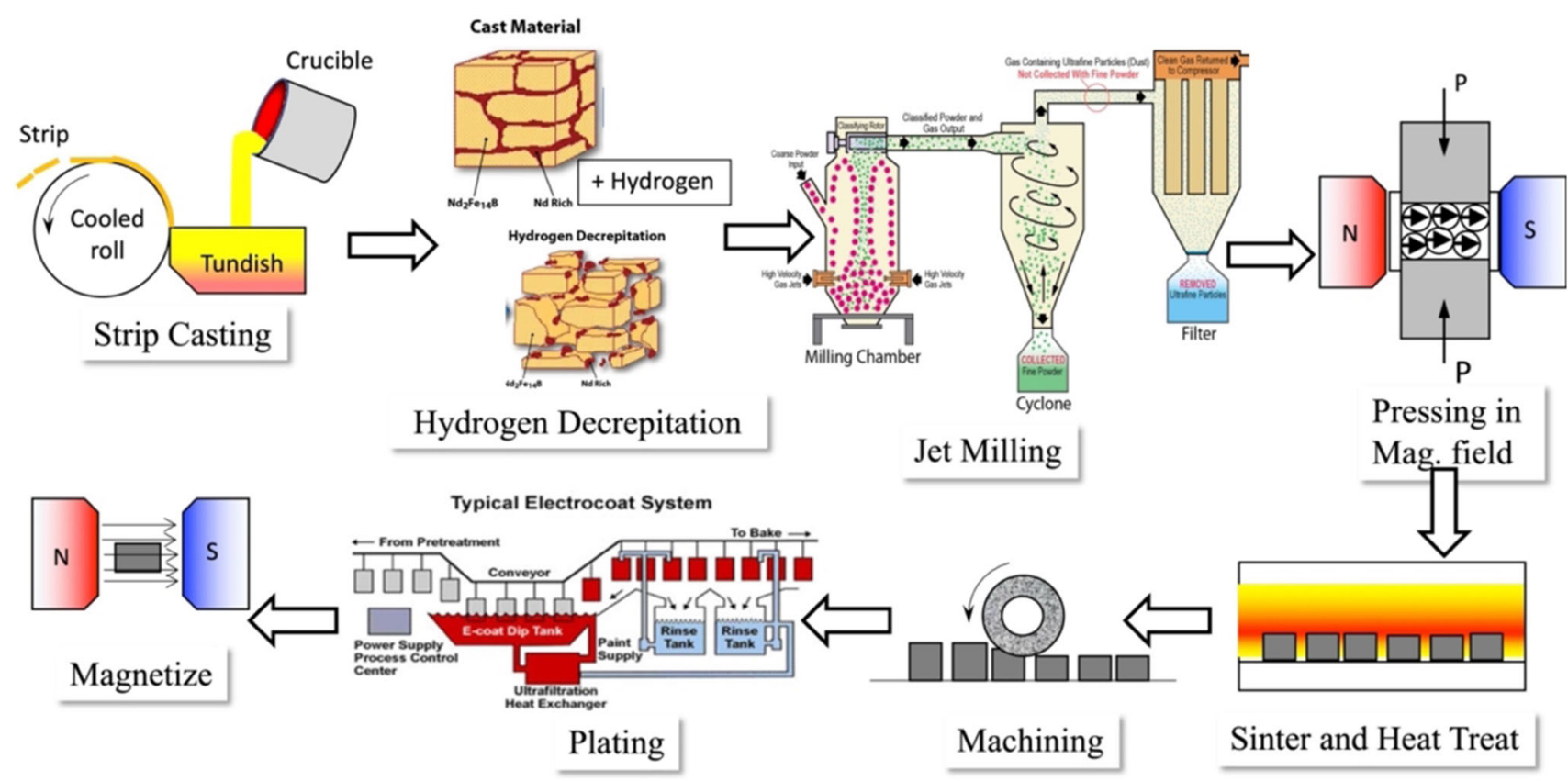

Fig. 8. Basic process steps for the Nd-Fe-B-based magnets. Adapted from Ormerod².

The best way to circumvent the formation of the $\alpha$ $\mathrm{Fe}$ phase is to rapidly cool the alloy through the peritectic temperature, so that formation of the $\alpha-F e$ is suppressed. In addition, the rapid cooling allows alloy to be produced with lower Nd content, resulting in higher remanence in the finished magnets. In the early stages of the development of sintered $\mathrm{Nd}$ magnets, the ingot was cast into book molds, whose casting cavities are slots with a cross section on the order of $1 \mathrm{~cm}$ or less in width, resulting in more rapid cooling of the ingot. This helped but did not solve the problem of $\alpha$-Fe precipitates. The problem was finally solved by the development of strip casting, a process where the molten alloy is first produced in a standard melt furnace and then poured into a trough-shaped tundish, which contains a long narrow slot-shaped nozzle. A sheet of molten alloy pours from the nozzle and is quenched on a rotating water-cooled drum to form a continuous sheet of cast alloy. This alloy sheet is typically $<1 \mathrm{~mm}$ thick, and, as with the melt spun ribbon, the sheet cracks into small flakes measuring from $5 \mathrm{~mm}$ to $10 \mathrm{~mm}$ in diameter when cooled. The cooling rate of the molten alloy is typically 500 $1000^{\circ} \mathrm{C} / \mathrm{s}$. Strip casting was a major development in the production of sintered Nd magnets and resulted in substantial improvements in magnetic properties. Today strip casting is the preferred alloy production method for Nd-Fe-B magnets.

\section{Comminution}

The strip cast flakes are then broken down using hydrogen decrepitation process. ${ }^{25}$ Hydrogen embrittles metals by entering the grain boundaries and creating uneven stress to grains. This causes microcracks that begin to propagate through the grain structure and makes the flakes friable. This is followed by jet milling to a narrow particle size distribution around $5 \mu \mathrm{m}$, which produces a powder consisting of single-crystal particles while eliminating ultrafine RE-rich particles. The resultant powder is then pressed under an aligning field, similar to the powder alignment process used for the Sm-Co magnets.

\section{Sintering and Heat Treatment}

The sintering of Nd-Fe-B permanent magnets is carried out in inert gas atmospheres or under vacuum. The sintering treatment should result in a magnet with a high density and no appreciable grain growth. A constant and well-defined sintering temperature is necessary to ensure the magnet has no open porosities which could lead to oxidation and aging during use. This requires the density to be $>98 \%$ of theoretical density.

An additional isothermal heat treatment is necessary for Nd-Fe-B magnets to develop the optimum coercivity and loop shape properties. As with SmCo-based magnets, during the sintering operation, the pressed product volume reduces to the final magnet body. This shrinkage depends upon production factors and the final magnet shape and size. This results in some variation in magnet size, and therefore a machining operation is necessary.

\section{Machining}

The magnet shape and size mainly impact the pressing and machining stages of the production 
process. Small magnets are pressed as large blocks with either uniaxial or isostatic pressing. Larger magnets are either uniaxially pressed with multicavity tooling or machined from larger blocks. The finished magnets are then machined using wire saws, wire electrical discharge machining (EDM), or abrasive wheel slitting machines.

When magnets are removed from the sintering and anneal/heat treatment furnace, they will have shrunk about 7-25\% linearly. The shrinkage will be anisotropic. Depending on the composition and sintering temperatures, the shrinkage parallel to the magnetic alignment direction might vary from $17 \%$ to $25 \%$, while the shrinkage perpendicular to the magnetic alignment direction might vary from $7 \%$ to $13 \% .{ }^{26}$ Due to this large shrinkage and some localized variability from differential green density, it is necessary to grind the poles surfaces flat and parallel, and it is frequently necessary to grind other magnet faces to meet finished product dimensions.

Magnets which have been machined (sliced, ground, or EDM) have sharp edges and corners making them subject to easy chipping and fracture. Furthermore, coating will not uniformly cover a sharp edge, creating either an undercoated region adjacent to the edge or a large, rounded coating layer on the edge. To avoid these problems, magnets are treated via machine chamfering or, more often, by vibratory honing. This has the secondary feature of enhancing the smoothness of the magnet surfaces, thus improving the uniformity of coating. The most common method and equipment used to accomplish vibratory hone is a vibratory tumbler (e.g., SWECO Finishing Mill).

\section{Coating}

Magnets based on the $\mathrm{Nd}_{2} \mathrm{Fe}_{14} \mathrm{~B}$ intermetallic are susceptible to corrosion and require a corrosionresistant coating for normal applications. A combination of magnet processing, alloy chemistry, and microstructural improvements over the years has dramatically improved the corrosion stability of $\mathrm{Nd}-$ Fe-B magnets. ${ }^{27}$ Despite these improvements, NdFe-B magnets still require a corrosion protection coating. The optimum coating must be thin to minimize air gaps in the magnetic circuit and uniformly covering all magnet surfaces. The coating technology must involve little or no hydrogen and be applicable to wide range of magnet shapes and sizes. Typical coatings and their performance under salt spray testing is shown in Table III. . $^{289}$

\section{Magnetization}

Magnetization of Nd-Fe-B is carried out using similar methods and equipment as described earlier for Sm-Co-based magnets.

\section{Dy Diffusion}

In addition to poor corrosion resistance, Nd-Fe-B suffers from a high thermal coefficient of coercivity, $\beta$, which can be as high as $-0.65 \% /{ }^{\circ} \mathrm{C}$ compared to alnico magnets with a $\beta$ of $-0.01 \% /{ }^{\circ} \mathrm{C}$. This is a major issue in any application operating at elevated temperature, particularly when the magnets are subject to a significant demagnetizing field, e.g., a servo motor works significantly above room temperature at high-torque operating conditions, which can lead to demagnetization of the magnets and loss of motor performance or even total motor failure. The solution today for increasing the operating temperature of $\mathrm{Nd}-\mathrm{Fe}-\mathrm{B}$ magnets was discovered back in 1984, namely, the addition of heavy $\mathrm{RE}$ elements (HREEs) and in particular Dy and Tb (see Fig. 9) ${ }^{30}$ Dy content increases the maximum operating temperature from around $80-220^{\circ} \mathrm{C}$ with an addition of $12 \mathrm{wt} . \%$. Figure 5 shows the typical NdFe-B grade designations that have been developed based on Dy content and the corresponding maximum recommended operating temperatures. Typical application areas for each grade are also indicated in the figure.

Beginning in 2011, the Chinese government placed restrictions on the export of $\mathrm{RE}$ elements and products, which results in supply disruptions, speculative stockpiling, and extraordinary price increases, e.g., $\mathrm{Dy}_{2} \mathrm{O}_{3}$ prices increased 12 times and $\mathrm{Tb}_{2} \mathrm{O}_{3}$ over 6 times in 2011. ${ }^{31}$ This led to extensive research efforts throughout the industry, academia, and national research laboratories to find ways to reduce the Dy content for higher temperature/coercivity grades. Before the 2011 rare earth crisis, Dr. Nakamura reported that coating Nd-Fe-B powders with $\mathrm{Dy}_{2} \mathrm{O}_{3}, \mathrm{DyF}_{3}$, or $\mathrm{TbF}_{3}$ before the heat treatment resulted in a great enhancement in

Table III. Coating material specifications

\begin{tabular}{|c|c|c|}
\hline Coating & Thickness range (microns) & Salt fog resistance $\left(35^{\circ} \mathrm{C} / 5 \% \mathrm{NaCl}\right)(\mathrm{h})$ \\
\hline Electroless nickel & 25 max. & $>500$ \\
\hline $\mathrm{Ni}-\mathrm{Cu}-\mathrm{Ni}$ & $10-20$ & $>500$ \\
\hline Epoxy (E-coat) & $15-60$ & $>240$ \\
\hline Parylene (C/D/HT) & $7-50$ & $>100$ \\
\hline Aluminum IVD & $7-25$ & $>500$ \\
\hline Zinc & $25 \max$ & $>96$ \\
\hline Epoxy powder coat & $50-125$ & $>500$ \\
\hline
\end{tabular}




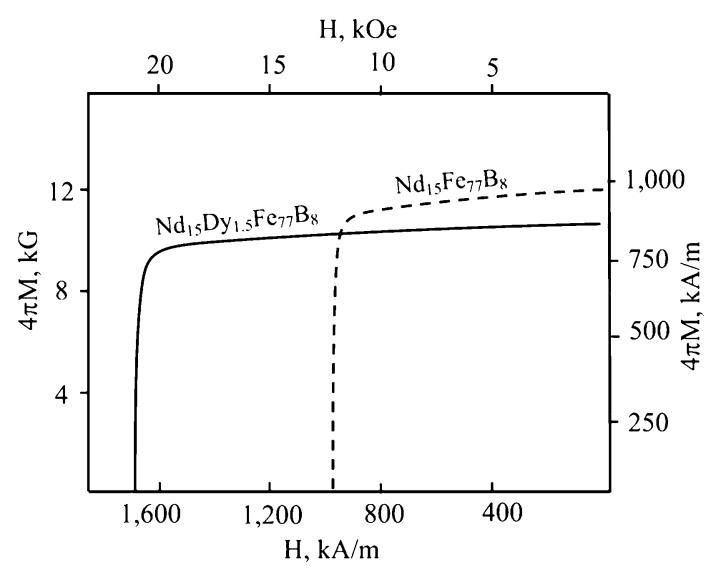

Fig. 9. Comparison of the demagnetization curves of a $\mathrm{Nd}-\mathrm{Fe}-\mathrm{B}$ magnet and a Nd-Fe-B-Dy magnet. Adapted from M. Sagawa. ${ }^{30}$

coercivity without significant reduction in remanence. $^{32}$

Several major magnet producers developed similar approaches to this problem by using processes that essentially enriched the grain boundary regions of the main $\mathrm{Nd}_{2} \mathrm{Fe}_{14} \mathrm{~B}$ phase with HREEs by a variety of solid state, gaseous, and other forms of diffusion technologies. Since the coercivity in these materials is controlled at the grain boundary region, these Dy-diffusion techniques have the advantages of enhancing coercivity, while at the same time minimizing the loss of remanence and reducing the amount of Dy required compared to the conventional bulk alloying methods.

One example is the TDK HAL (high anisotropy field layer) process. ${ }^{33}$ In the HAL process, a Dy source for diffusion is applied to the surface of a sintered neodymium magnet substrate and then heat treated. The Dy diffuses throughout the grain boundary regions of the material via the grain boundary Nd-rich phases that surround the $\mathrm{Nd}_{2} \mathrm{Fe}_{14} \mathrm{~B}$ main phase particles. Since the heat treatment used in the HAL process is performed at relatively low temperatures, Dy does not diffuse into the interior of the crystalline particles.

TDK claims a $20-50 \%$ reduction in Dy is possible with their HAL technology with a $3-5 \%$ increase in $\mathrm{B}_{\mathrm{r}}$. Today, all the major Nd-Fe-B manufacturers offer some variants of grain boundary diffused or modified reduced Dy content grades. So why do the standard bulk alloy grades still exist? The answer is processing cost versus HREE raw material price. All these grain boundary diffusion processes are rather slow, primarily because of the low temperature annealing required. So, for the economics to be favorable, Dy raw material prices must be above a certain level. Of course, with the expected growth of EV/HEVs over the next 10 years, demand for Dy and $\mathrm{Tb}$ will exceed supply at some point for conventional alloyed grades. At this point, grain boundary diffused grades will take over for the highest operating temperature applications.

\section{Alnico}

Alnico magnets consist mostly of aluminum, nickel, and cobalt balanced with iron and small amounts of copper and refractory metals. It is one of the oldest known modern-era commercial permanent magnets started at the beginning of the twentieth century in Japan by T. Mishima. ${ }^{34,35}$ They still fascinate scientists around the world with their unique structural and magnetic features, as well as their great unlocked potential. ${ }^{36-41}$ Alnico magnets are widely used in microphones, loudspeakers, electric guitar pickups, electric motors, travelling-wave tubes, Hall sensors, etc.

The first material in the family of alnico magnets was an aluminum-nickel-iron alloy that did not contain cobalt. Attempts to increase the coercivity and energy product required additions of cobalt and minor amounts of other metals. Many grades were created from the 1930s through the mid-1970s. Each successive improvement in material resulted in a new grade with names that were more-or-less sequential. Thus, we have alnico grades 1 through 6 . The next significant improvements in properties were made by processing; alnico 5 was quenched from the melt on a chilled surface to obtain oriented crystal growth, grade 5DG. Further improvement was accomplished by field processing of the improved structure to produce grade 5-7. Since the 5-7 composition was the same as alnico 5 but with markedly improved properties, instead of naming it 7 , it was given the hyphenated name alnico 5-7. Further improvements in coercivity through the addition of titanium resulted in grades 8 and $9\left((B H)_{\max } 83.6 \mathrm{~kJ} / \mathrm{m}^{3}\right.$ (10.5 MGOe), $B_{\mathrm{r}} 1.1 \mathrm{~T}$ $(11.2 \mathrm{kG})$, and $\left.H_{\mathrm{ci}} 120 \mathrm{kA} / \mathrm{m}(1.5 \mathrm{kOe})\right)$. Details of compositions and properties of each grade can be found in the standard specifications for permanent magnet materials. ${ }^{42}$ Based solely on available remanent magnetization the energy products of alnico can easily surpass $239 \mathrm{~kJ} / \mathrm{m}^{3}$ (30 MGOe). For example, in alnico 9 with $B_{\mathrm{r}}$ of $1.12 \mathrm{~T}(11.2 \mathrm{kG})$, the theoretical $(B H)_{\max }, 4 \pi B_{\mathrm{r}}{ }^{2} / 4$, equals $250 \mathrm{~kJ} / \mathrm{m}^{3}$ (31.4 MGOe). However, such is only possible if the coercivity reaches half of $B_{\mathrm{r}}$, i.e., $H_{\mathrm{ci}}$ of $477-517 \mathrm{~A} /$ $\mathrm{m}(6-6.5 \mathrm{kOe})$, at a perfectly square demagnetization curve. More realistically, considering imperfections of spinodal decomposition, the theoretical $(B H)_{\max }$ of the rare-earth-free magnet is predicted to reach $159 \mathrm{~kJ} / \mathrm{m}^{3}$ (20 MGOe). ${ }^{43,44}$

Alnico is known for its exceptional thermal characteristics. It has the best temperature coefficients of any magnet materials, $\alpha=-0.03$ to -0.02 , $\beta=-0.02 \% /{ }^{\circ} \mathrm{C}$ to $0.01 \% /{ }^{\circ} \mathrm{C}$ within $20-100^{\circ} \mathrm{C}$. Its operating temperature can be up to $450-550^{\circ} \mathrm{C}$. Moreover, alnico has high resistance to corrosion. However, alnico magnets have limitations, with the most significant being their low coercivity. Although theoretically it is predicted to reach $318-397 \mathrm{kA} / \mathrm{m}$ (4-5 kOe), it rarely reaches $199 \mathrm{kA} / \mathrm{m}(2.5 \mathrm{kOe})$. Low coercivity makes alnico prone to 

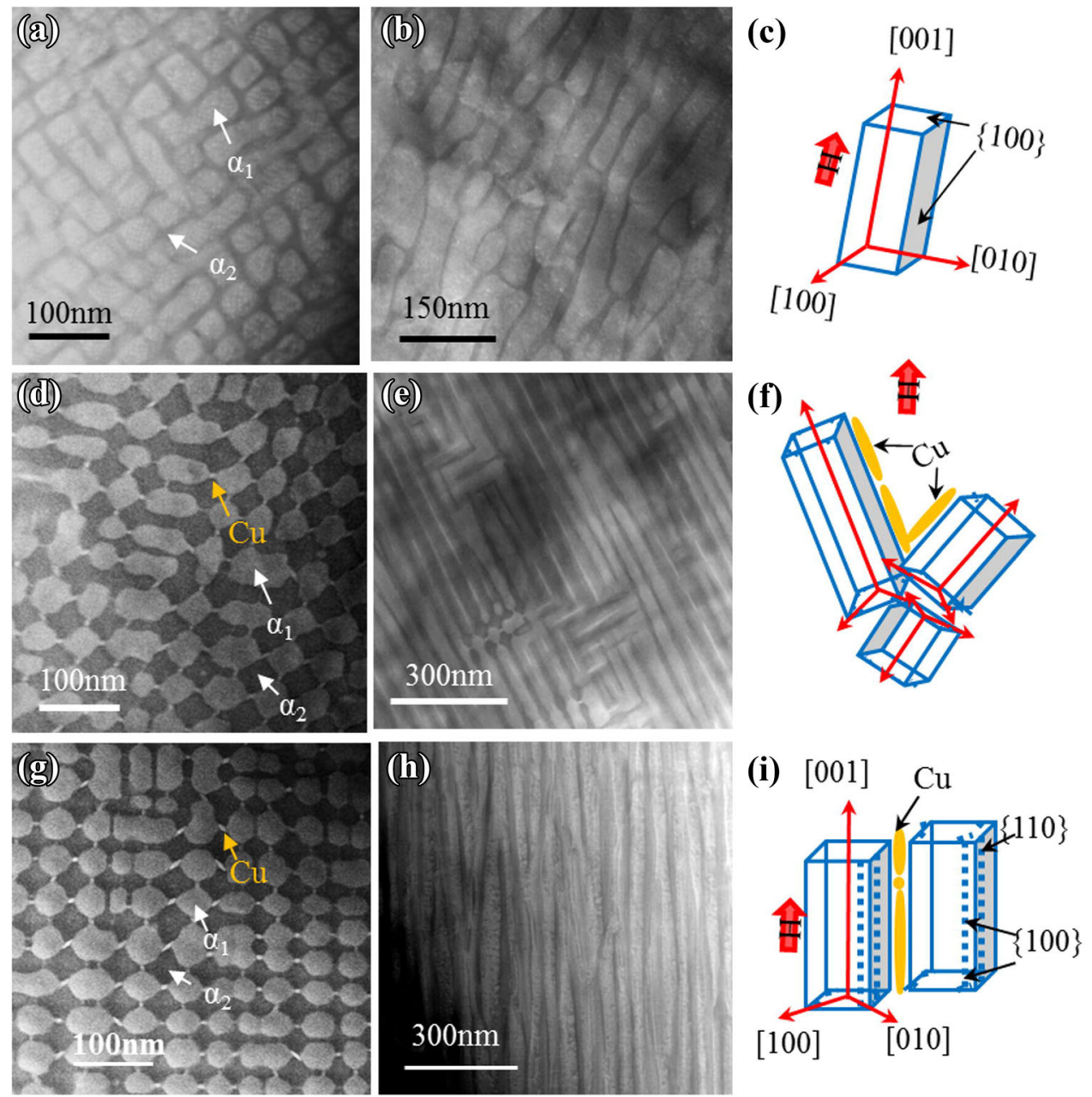

Fig. 10. HAADF STEM images and schematic of $\alpha_{1}$ phase morphology of different alnico alloys: (a) alnico 5-7, transverse; (b) alnico 5-7, longitudinal; (c) model of $\alpha_{1}$ phase in alnico 5-7; (d) alnico 8, transverse; (e) alnico 8, longitudinal; (f) model of $\alpha_{1}$ phase in alnico 8; (g) alnico 9, transverse; (h) alnico 9, longitudinal; (i) model of $\alpha_{1}$ phase in alnico 9. Reprinted with permission. ${ }^{40}$

demagnetization. Sintered alnico magnets are usually limited to small-to-medium sizes and simpler shapes. Complex cast alnico needs sand mold tooling, which can be expensive if existing tooling is not available.

Alnico's hard magnetic properties strongly depend on the perfection of the spinodal decomposition and proper phase separation of the coherent spinodal components, i.e., magnetic $\mathrm{Fe} / \mathrm{Co}$-rich $\alpha_{1}$ phase and non-magnetic Al/Ni-rich $\alpha_{2}$-phase. ${ }^{45}$ Figure 10 shows STEM images and schematic of $\alpha_{1}$ phase morphology of different alnico alloys. ${ }^{40}$ Since both phases are crystallographically cubic, they have small magnetocrystalline anisotropies and so the magnetic energy is dependent on the shape of magnetic phase (long $\mathrm{Fe} / \mathrm{Co} \alpha_{1}$-phase rods in a bunch) as well as spatial and magnetic separation between those rods. The longer the rods and the better they are separated, the more anisotropic alnico is and more rectangular the magnetic hysteresis is.
There are two different manufacturing processes for alnico: cast alnico and sintered alnico. Cast alnico can be made into intricate and complex shapes. Sintered alnico offers slightly lower magnetic properties but better mechanical characteristics than cast alnico. Their fine grain structure results in highly uniform flux distributions and mechanical strength. Both casting and sintering of alnico usually involve an eight-step process as shown in Fig. 11. Casting process includes induction melting, casting, fettling, heat treatment, grinding, testing, coating, and magnetizing. Sintering of alnico also involves induction melting, and then the ingot has to be milled into fine particles, pressed, sintered, tested, coated, and magnetized.

The induction melting is performed at a high temperature $>1750^{\circ} \mathrm{C}$. Excessive low-meltingpoint aluminum is added to make up the waste at such high temperature. The melt is poured into shells and/or green sand molds. The shells are made using a pattern plate and molding machine. After 


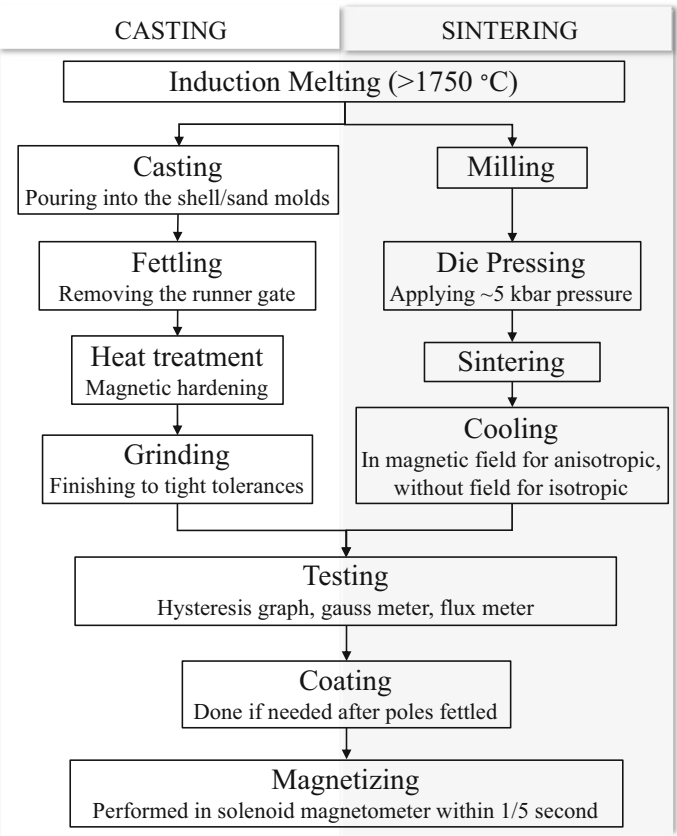

Fig. 11. Typical casting and sintering processes for alnico magnets.

casting, the running gates and other imperfections are removed by fettling on grinding wheels. The obtained magnets are then subjected to heat treatments, which usually involve heating to 1200 $1300^{\circ} \mathrm{C}$ for homogenization, cooling in a magnetic field, and magnetic annealing at $800-900^{\circ} \mathrm{C}$ for 8 $15 \mathrm{~min}$. The magnetic annealing facilitates controlled anisotropic spinodal decomposition of the uniform matrix material, i.e., helps the development of an anisotropic spinodal microstructure. The final heat treatment is tempering at $680-550^{\circ} \mathrm{C}$ for 1-24 h, which is also known as the low-temperature draw. This is the stage where chemical separation between spinodal components is finalized and a maximum coercivity is achieved. Small magnets may be produced by sintering. In this process, the desired mixture of metal powders is pressed to shape and size in a die and then sintered at a temperature of approximately $1260^{\circ} \mathrm{C}$ in a hydrogen atmosphere.

Significant effort has been devoted to developing simple non-cast approaches for achieving [001] easy axis aligned alnico magnets. ${ }^{46-51}$ Abnormal grain growth (AGG) is detected during the compaction of the pre-alloyed gas atomized spherical powders. This leads to increased texturing control without the costly directional casting, i.e., energy product increases from $38 \mathrm{~kJ} / \mathrm{m}^{3}$ to $52 \mathrm{~kJ} / \mathrm{m}^{3}(4.8-$ 6.5 MGOe) primarily because of $\sim 24 \%$ increase of loop squareness during the AGG process. The thermal gradient control and compression stress in combination with applied magnetic field have shown potential for mass production of net-shape alnico magnets with grain-aligned microstructure. ${ }^{47}$ Figure 12 shows the details of compression molding and sintering treatments of gas atomized pre-
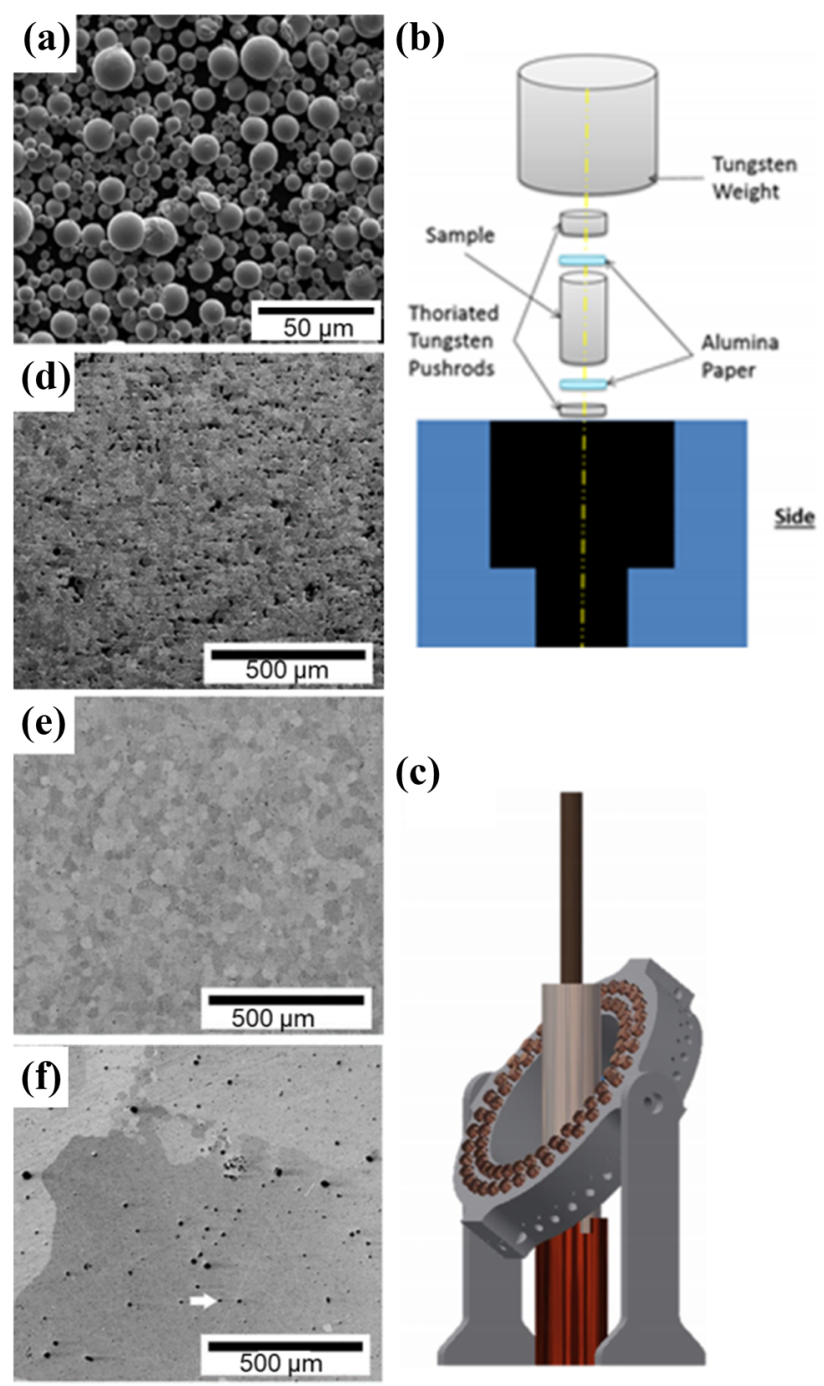

(c)

Fig. 12. Compression molding and novel sintering treatments of gas atomized pre-alloyed powders of alnico. (a) SEM micrograph of gas atomized pre-alloyed alnico 8 powder, (b) schematics of uniaxial loading apparatus for alnico specimen texturing; (c) magnetic templating setup with powder loading in center and Halbach array used to create specific angular orientations and field directions. (d-f) SEM (BSE) images of $1250^{\circ} \mathrm{C}$ sintered samples after $1 \mathrm{~h}, 4 \mathrm{~h}$, and $8 \mathrm{~h}$ sintering, respectively; the $8 \mathrm{~h} 99.6 \%$ dense sintered samples show large-grown grains and residual porosity (indicated by the arrow). Adapted from A. G. Kassen. ${ }^{49}$

alloyed powders of alnico. This process can be used in different powder metallurgical systems that also undergo the AGG process.

Additive manufacturing (AM) methods have been explored for alnico manufacturing. ${ }^{52}$ The commercial alnico magnets with the highest energy performance are produced by directional solidification followed by significant machining. These magnets achieve perfect columnar grain orientation but are costly. AM could significantly reduce the processing costs through production of near-shape parts with minimal machining if the texture control proves to be achievable. Both laser engineered net shaping and electron beam melting powder bed fusion 


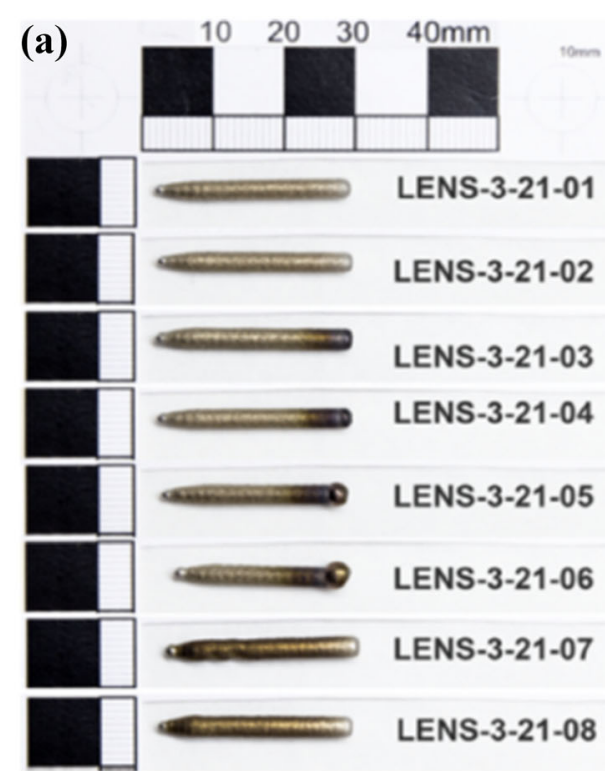

(b)

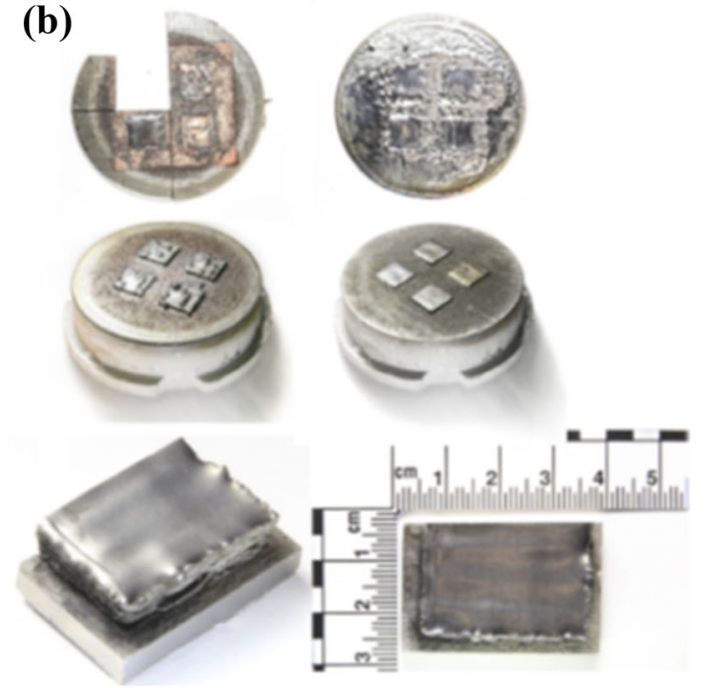

Fig. 13. Additively manufactured (AM) alnico magnets: (a) laser engineered net shaping (LENS)/directional energy deposition (DED) and (b) electron beam melting powder bed fusion (EBM/PBF) alnico 8 derivative samples. Reprinted from E. White, ${ }^{52}$, under the terms of the Creative Commons CC BY license. ${ }^{52}$

methods were tested for alnico additive manufacturing. ${ }^{52,53}$ Figure 13 shows the parts made with these two methods. The properties of the AM processed samples are less than ideal. A comprehensive processing optimization is needed to achieve the texture and consistency of their cast/ sintered counterparts. Nevertheless, the results of these preliminary additive manufacturing efforts demonstrate feasibility for near-shape processing of alnico, especially for parts with complex geometries.

\section{Ferrite}

Ferrite magnets are known for their low cost, good corrosion resistance, and high temperature stability up to $250^{\circ} \mathrm{C}$. Although their magnetic properties are far from those of the Nd-Fe-B magnet, their cost is remarkably low. With the rising demand for rare earth-based magnets for applications sensitive to weight or size, ferrite becomes a better choice for less energy-intensive applications such as power window/seats in vehicles, switches, fans, blowers in appliances, some power tools, and loudspeakers and buzzers in electro-acoustic devices.

Large-scale commercial permanent ferrite magnets production is dominated by the M-type hexaferrites because of their low material and production costs. Here, M-type refers to the compound formula $\mathrm{RFe}_{12} \mathrm{O}_{19}$, where $\mathrm{R}=\mathrm{Ba}, \mathrm{Sr}$, and $\mathrm{Pb}$. Barium hexaferrite $\left(\mathrm{BaFe}_{12} \mathrm{O}_{19}\right)$ was discovered in 1952 at the Philips Physics Laboratory and was marketed under the trade name Ferroxdure. ${ }^{54-56}$ The discovery was due to a mistake by an assistant who was supposed to make hexagonal lanthanum ferrite as a semiconductor material. ${ }^{57} \mathrm{~A}$ few years later, Philips introduced strontium hexaferrite $\left(\mathrm{SrFe}_{12} \mathrm{O}_{19}\right)$, which has better properties than barium hexaferrite. In the $1980 \mathrm{~s}$, several more hexagonal ferrites were developed, such as $W$-type $\left(\mathrm{RMe}_{2} \mathrm{Fe}_{16} \mathrm{O}_{27}\right.$, where $\mathrm{Me}=\mathrm{Fe}^{2+}, \mathrm{Ni}^{2+}, \mathrm{Mn}^{2+}$, etc. $)$, $X$-type $\left(\mathrm{RMeFe}_{28} \mathrm{O}_{46}\right), \mathrm{Y}$-type $\left(\mathrm{R}_{2} \mathrm{Me}_{2} \mathrm{Fe}_{12} \mathrm{O}_{22}\right)$, and $Z$-type $\left(\mathrm{R}_{3} \mathrm{Me}_{2} \mathrm{Fe}_{24} \mathrm{O}_{41}\right)$. Some of them possess magnetic properties superior to the $M$-type $\mathrm{SrFe}_{12} \mathrm{O}_{19}$ ferrite, but their relatively difficult processing makes them economically unpopular. ${ }^{58,59}$ Major improvement to the conventional ferrite occurred in the early $2000 \mathrm{~s}$, when $\mathrm{Ca}$, La, and Co were added to improve the $(B H)_{\max }$ from $30 \mathrm{~kJ} / \mathrm{m}^{3}$ to $33 \mathrm{~kJ} / \mathrm{m}^{3}$ (3.8-4.2 MGOe) to $37-40 \mathrm{~kJ} / \mathrm{m}^{3}$ (4.6-5.0 MGOe), ${ }^{60-}$ with further improvement to $41-45 \mathrm{~kJ} / \mathrm{m}^{3}(5.2-$ $5.6 \mathrm{MGOe}$ ) in the late $2000 \mathrm{~s}^{63,64}$

Commercial ferrite magnets have a wide range of products, with sintered anisotropic magnets as the strongest and the flexible plastoferrites as the weakest (Table IV). The processing routes for these two products are reviewed below. Figure 14 shows the processing flow.

The manufacturing process of sintered anisotropic magnets is a classical ceramic process involving calcining for accurate composition, milling for fine particle size, wet pressing in a magnetic field for particle alignment, and sintering for high density. ${ }^{65}$

The powder synthesis starts with mixing $\mathrm{BaCO}_{3}$ or $\mathrm{SrCO}_{3}$ and $\mathrm{Fe}_{2} \mathrm{O}_{3}$ feedstock powders. The ratio of $\mathrm{Fe}_{2} \mathrm{O}_{3} / \mathrm{SrCO}_{3}$ is critical for obtaining the magnet with a balanced remanence and coercivity. Excessive $\mathrm{BaCO}_{3}$ or $\mathrm{SrCO}_{3}$ dilutes magnetic moments and lowers remanence, while excessive $\mathrm{Fe}_{2} \mathrm{O}_{3}$ cause large grain growth and lowers coercivity. A small amount of $\mathrm{SiO}_{2}(0.1-1.0$ wt.\%) may prohibit grain growth, allowing calcination at higher temperature. The calcination temperature is typically between $1250^{\circ} \mathrm{C}$ and $1300^{\circ} \mathrm{C}$. If the temperature is too low, the solid-state reaction will be incomplete, and the resulting material will be inhomogeneous; if the temperature is too high, excessive grain growth will 
Table IV. Key magnetic properties of various ferrite magnets

\begin{tabular}{|c|c|c|c|c|c|c|}
\hline & $\mathrm{Br}(\mathbf{T})$ & $\mathrm{Br}(\mathbf{k G})$ & Hc, $(\mathbf{k A} / \mathbf{m})$ & He (kOe) & $(\mathrm{BH})_{\max }\left(\mathbf{k J} / \mathrm{m}^{\mathbf{3}}\right)$ & $(\mathrm{BH})_{\max }(\mathrm{MGOe})$ \\
\hline Sintered iso & $0.20-0.23$ & $2.0-2.3$ & $136-152$ & $1.7-1.9$ & $6.4-8.4$ & $0.8-1.1$ \\
\hline Sintered aniso (high $\mathrm{Br}$ ) & $0.39-0.43$ & $3.9-4.3$ & $192-200$ & $2.4-2.5$ & $28.8-34.4$ & $3.6-4.3$ \\
\hline Sintered aniso (high Hc) & $0.35-0.40$ & $3.5-4.0$ & $260-292$ & $3.2-3.7$ & $22.4-30.4$ & $2.8-3.8$ \\
\hline Bonded flexible iso & $0.1-0.17$ & $1.0-1.7$ & $76-128$ & $1.0-1.6$ & $2.4-5.6$ & $0.3-0.7$ \\
\hline Bonded flexible aniso & $0.20-0.25$ & $2.0-2.5$ & $140-176$ & $1.8-2.2$ & $8.0-12.0$ & $1.0-1.5$ \\
\hline Bonded rigid iso & $0.13-0.14$ & $1.3-1.4$ & $72-84$ & $0.9-1.1$ & $2.8-3.2$ & $0.3-0.4$ \\
\hline Bonded rigid aniso & $0.20-0.30$ & $2.0-3.0$ & $120-185$ & $1.5-2.3$ & $7.3-16.0$ & $1.0-2.0$ \\
\hline
\end{tabular}

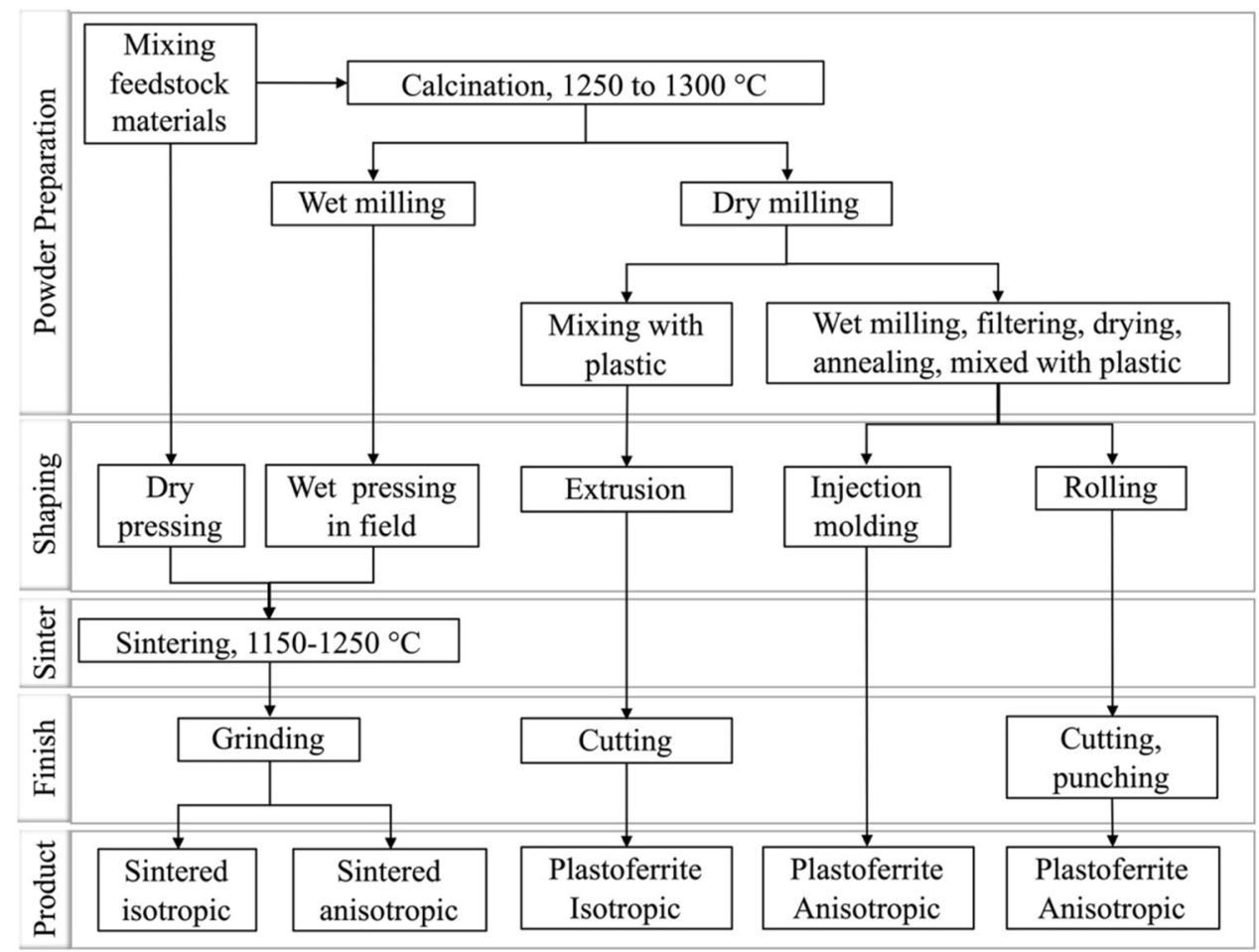

Fig. 14. Processing routes for ferrite magnets. Adapted from Van Den. ${ }^{56}$

occur, causing low coercivity. After calcination, the block is wet milled to powders with an average particle size in the range of $0.7-0.9 \mu \mathrm{m}$. Particle sizes $<0.7 \mu \mathrm{m}$ create problems in compaction and sintering, while particles $>0.9 \mu \mathrm{m}$ affects coercivity.

The fine ferrite particles are mixed with water (about 15 vol.\%) forming a slurry, then placed in a $1 \mathrm{~T}$ magnetic field perpendicular to the mechanical pressing direction. Mixing with water improves alignment as well as density. Polyvinyl alcohol and camphor can be used as a binder during the compression, and they are removed during the sintering stage. Compaction stress in the range of $5-15 \mathrm{MPa}$ is sufficient in wet pressing. It is possible to manufacture both isotropic and anisotropic magnets by dry pressing, but it would require much higher stress, in the range of 40-80 MPa.

The ferrite magnet sintering process is carried out at $1150-1200^{\circ} \mathrm{C}$, about $100^{\circ} \mathrm{C}$ lower than the calcination temperature to avoid the grain growth.
Addition of $\mathrm{SiO}_{2}$ may facilitate densification without grain growth by liquid-phase sintering. ${ }^{66}$ Silica is insoluble in the ferrite phase, segregates to grain boundaries, and hinders grain boundary motion. ${ }^{67}$ The magnetic texture is enhanced by the controlled growth of well-aligned grains at the expense of lessaligned grains. The average grain size of sintered magnets is about $1 \mu \mathrm{m}$, which is bigger than the domain size $(0.5 \mu \mathrm{m})$, but small enough to prevent domain reversal. In addition to $\mathrm{SiO}_{2}, \mathrm{Al}_{2} \mathrm{O}_{3}, \mathrm{Cr}_{2} \mathrm{O}_{3}$, and $\mathrm{CaO}$ can also be used alternatively or in combination to promote the densification. A major problem during the hexaferrite sintering process is the anisotropic shrinkage. It can be as high as $25 \%$ parallel and $10 \%$ perpendicular to the magnetization direction, respectively. This problem can be addressed when designing the pressing dies. The thermal expansion coefficient is also anisotropic and can lead to fracture during cooling. Since sintered ferrites are hard and brittle, they are typically cut 
with a saw and ground with diamond tools to the specified dimensions. The final step of making a ferrite magnet is to magnetize it with a 955-1194 A/ m (12-15 kOe) field (2.5-3 times higher than $\left.H_{\mathrm{c}}\right)$.

Useful magnets can be made by bonding $\mathrm{Sr}$ or $\mathrm{Ba}$ ferrite powders in various resins, plastics, or natural rubber. If no special steps are taken, the material is isotropic and energy product is unlikely to exceed $5.5 \mathrm{~kJ} / \mathrm{m}^{3}(0.7 \mathrm{MGOe})$. If good flexibility is required, the proportion of ferrite powder cannot be too large, and the overall magnetic pull force becomes considerably lower. A number of processing techniques, such as compression molding, injection molding, calendering, etc., may be employed for making polymer bonded magnets. It is possible to make anisotropic magnets by carrying out the processes under a magnetic field. By alignment of powders, it is possible to achieve energy products as high as $12 \mathrm{~kJ} / \mathrm{m}^{3}$ (1.5 MGOe) in bonded ferrite magnets. Finishing plastoferrites consist of cutting (or punching) the desired shapes out of rolled laminates. More information about the bonded magnet process can be found in the second paper reviewing bonded magnet fabrication processes.

\section{Sm-Fe-N}

Since the discovery of the samarium-iron-nitride $\left(\mathrm{Sm}_{2} \mathrm{Fe}_{17} \mathrm{~N}_{3}\right)$ intermetallic compound with high saturation magnetization and a large magnetocrystalline anisotropy field, it has been considered a candidate for high-performance permanent magnets comparable to Nd-Fe-B magnets. ${ }^{68,69}$ However, a fully dense $\mathrm{Sm}-\mathrm{Fe}-\mathrm{N}$ magnet has not yet been commercialized even though $>25$ years have elapsed since the discovery of the $\mathrm{Sm}_{2} \mathrm{Fe}_{17} \mathrm{~N}_{3}$ intermetallic compound. This is because Sm-Fe-N bulk magnets cannot be produced by the sintering or hot pressing of Sm-Fe-N powder since the compound is unstable above about $500^{\circ} \mathrm{C}$. The $\mathrm{Sm}-\mathrm{Fe}-\mathrm{N}$ powders are synthesized using the reduction diffusion method. First, $\mathrm{SmCl}_{3}, \mathrm{Fe}, \mathrm{Ca}$, and $\mathrm{CaH}_{2}$ are mixed and calcined at $760-860^{\circ} \mathrm{C}$ to form $\mathrm{SmFe}$ alloy; then, after chemical separation, the $\mathrm{SmFe}$ alloy is chalked and nitrided to form the Sm-FeN powders. ${ }^{70}$ The powders are used in either injection molded or compression bonded magnets. Several lowtemperature powder consolidation techniques have been attempted with $\mathrm{Sm}-\mathrm{Fe}-\mathrm{N} .{ }^{71-73}$ Daido Electronics used melt-spinning method to obtain Sm-Fe flakes and then heat treated the flakes with nitrogen to obtain $\mathrm{Sm}-\mathrm{Fe}-\mathrm{N}$ powders. These powders were used to produce a range of magnet grades with injection molding and compression bonding method. ${ }^{74} \mathrm{Mag}-$ netic performances of up to $(B H)_{\max }$ of $112 \mathrm{~kJ} / \mathrm{m}^{3}$ (14 MGOe) have been achieved. With the improved corrosion and heat resistance, bonded Sm-Fe-N magnets are suitable for a variety of applications, such as immersible pumps, cell phones, and sensors. More information on the low-temperature powder processing and bonded magnet manufacturing methods can be found in the second paper reviewing novel magnet fabrication processes.

\section{FUTURE DIRECTION AND SUMMARY}

PM's properties are highly sensitive to its microstructure, which in turn is dependent on the manufacturing process. The current magnet manufacturing process is less ideal in waste generation and product variability. The brittleness of the RE compounds causes microcrack generation during rapid cooling and fracture during machining. Sm-Co based magnets are the most brittle all RE-based magnets, with machining failure rate up to $20 \%$ due to its low fracture toughness $\left(1.9-2.9{\left.\mathrm{MPa}-\mathrm{m}^{1 / 2}\right)}^{75}\right.$ Nd-Fe-B has somewhat better toughness (2.5$5.5 \mathrm{MPa}-\mathrm{m}^{1 / 2}$ ) but is still brittle in nature. ${ }^{76}$ Nearnet shape fabrication of sintered magnets may significantly reduce the waste due to machining.

The performance of magnets varies from batch to batch, block to block, and magnet to magnet. These differences can be attributed to the slight variation of thermal history each magnet experienced during the fabrication process. For example, each sintering batch may contain 10 or more blocks, each weighing $>2 \mathrm{~kg}$. These blocks cannot be taken in or out of the furnace at the same time and the block center always cools more slowly than the spot near the surface. Smaller batch and block sizes may reduce variability but will increase cost. In the past decade, many novel process techniques have been explored to improve both properties and manufacturing efficiency. Examples include extrusion, additive manufacturing, spark plasma sintering, shock compaction, and thermomagnetic processing. These methods will be reviewed in the sequel paper, "Manufacturing Processes for Permanent Magnets: Part II-Bonding and Emerging Methods."

\section{ACKNOWLEDGEMENTS}

This work is supported by the Critical Materials Institute (CMI), an Energy Innovation Hub funded by the US Department of Energy (DOE), Office of Energy Efficiency and Renewable Energy, Advanced Manufacturing Office. Ames Laboratory is operated for the US Department of Energy by Iowa State University of Science and Technology under contract no. DE-AC02-07CH11358. Work at LLNL and ORNL was performed under contracts DEAC52-07NA27344 and DE-AC05-00OR22725, respectively. The US government retains and the publisher, by accepting the article for publication, acknowledges that the US government retains a nonexclusive, paid-up, irrevocable, worldwide license to publish or reproduce the published form of this manuscript, or allow others to do so, for US government purposes. DOE will provide public access to these results of federally sponsored research in accordance with the DOE Public Access Plan (http://energy.gov/downloads/doe-public-access-plan). 


\section{CONFLICT OF INTEREST}

On behalf of all authors, the corresponding author states that there is no conflict of interest.

\section{OPEN ACCESS}

This article is licensed under a Creative Commons Attribution 4.0 International License, which permits use, sharing, adaptation, distribution and reproduction in any medium or format, as long as you give appropriate credit to the original author(s) and the source, provide a link to the Creative Commons licence, and indicate if changes were made. The images or other third party material in this article are included in the article's Creative Commons licence, unless indicated otherwise in a credit line to the material. If material is not included in the article's Creative Commons licence and your intended use is not permitted by statutory regulation or exceeds the permitted use, you will need to obtain permission directly from the copyright holder. To view a copy of this licence, visit http://creativecommons.org/licenses/by/4.0/.

\section{REFERENCES}

1. B.D. Cullity, Introduction to Magnetic Materials (AddisonWesley Pub. Co, Reading, 1972).

2. J. Ormerod, Rare earth magnets: yesterday, today and tomorrow. Magnetics (2019). Orlando. https://www.linkedi n.com/pulse/rare-earth-magnets-yesterday-today-tomorrowjohn-ormerod/. Accessed 22 July 2021.

3. N. Dushyantha, N. Batapola, I.M.S.K. Ilankoon, S. Rohitha, R. Premasiri, B. Abeysinghe, N. Ratnayake, and K. Dissanayake, Ore Geol. Rev. 122, 103521 (2020).

4. E.A. Nesbitt, and J.H. Wernick, Rare Earth Permanent Magnets (Academic Press, New York, 1973).

5. K.J. Strnat, J. Magn. Magn. Mater. 7, 351 (1978).

6. A. Menth, H. Nagel, and R.S. Perkins, Annu. Rev. Mater. Res. 8, 21 (1978)

7. J.D. Livingston, in Chalmers Anniversary Volume, 1st edn. ed. by J.W. Christian, P. Haasen, and T.B. Massalski (Pergamon Press, Oxford, 1981), pp. 243-268.

8. J. Ormerod, J. Less-Common Met. 111, 49 (1985).

9. K.J. Strnat, Proc. IEEE 78, 923 (1990).

10. M.J. Kramer, R.W. McCallum, I.A. Anderson, and S. Constantinides, JOM 64, 752 (2012).

11. K. Strnat, G. Hoffer, and A. Ray, IEEE Trans. Magn. 2, 489 (1966).

12. J.J. Croat, Rapidly Solidified Neodymium-Iron-Boron Permanent Magnets (Woodhead Publishing, Duxford, 2017).

13. R. Skomski, and J.M.D. Coey, Scr. Mater. 112, 3 (2016).

14. J.M.D. Coey, Magnetism and Magnetic Materials (Cambridge University Press, Cambridge, 2010).

15. J.D. Widmer, R. Martin, and M. Kimiabeigi, Sustain. Mater. Technol. 3, 7 (2015).

16. R. Castilloux, Rare Earth Elements: Small Market, Big Necessity (Adamas Intelligence, 2019). http://www.adamasi ntel.com/wp-content/uploads/2019/06/Adamas-IntelligenceRare-Earths-Small-Market-Big-Necessity-Q2-2019.pdf. Accessed 22 July 2021.

17. U.S. DRIVE Partnership, Electrical and Electronics Tech Team Roadmap (US DOE Vehicle Technologies Office, 2017). https://www.energy.gov/sites/default/files/2017/11/f3 9/EETT\%20Roadmap\%2010-27-17.pdf. Accessed 21 July 2021.

18. Green Car Congress, BCG forecasts electrified vehicles to take half of global auto market by 2030 ; hybrids to dominate (2017). https://www.greencarcongress.com/2017/11/2017110 3-bcg.html. Accessed 22 April 2021.
19. J. P. Morgan, Driving into 2025: The Future of Electric Vehicles (J. P. Morgan, 2018). https://www.jpmorgan.com/g lobal/research/electric-vehicles. Accessed 22 July 2021.

20. IEA, Gloval EV Outlook 2021 (IEA, Paris, 2021). https://www. iea.org/reports/global-ev-outlook-2021. Accessed 22 July 2021.

21. U.S. Department of Energy, Critical Materials Strategy (Washington D.C., 2011).

22. U.S. Geological Survey, Rare Earths Statistics and Information (Reston, VA, 2021). U.S. Geological Survey, Mineral Commodity Summaries, Rare Earth Statistics and Information (published January 2021), Accessed 22 April 2021 at URL https://pubs.usgs.gov/periodicals/mcs2021/mcs2021-ra re-earths.pdf.

23. J. Liu, Sm-Co Permanent Magnets and Their Applications (Dayton, OH, 2008)

24. T. Ojima, S. Tomizawa, T. Yoneyama, and T. Hori, IEEE Trans. Magn. 13, 1317 (1977).

25. P.J. McGuiness, E. Devlin, I.R. Harris, E. Rozendaal, and J. Ormerod, J. Mater. Sci. 24, 2541 (1989).

26. K. Majima, Y. Kaneko, S. Katsuyama, and H. Nagai, Mater. Trans. JIM 35, 473 (1994).

27. Curtiss-Wright, 1000 Hour Salt Spray Resistance of Reare Earth Magnets (EM Coating, 2015). https://www.emcoating suk.co.uk/1000-hour-salt-spray-resistance-of-rare-earth-ma gnets/. Accessed 22 July 2021.

28. H.H. Man, H.C. Man, and L.K. Leung, J. Magn. Magn. Mater. 152, 40 (1996).

29. J. Ormerod, Fully Dense Rare Earth Magnets by Powder Metallurgical Processing (Bunting-Dubois, 2021), https://b unting-dubois.com/tech-briefs/types-of-rare-earth-magnetspart-1/. Accessed 22 July 2021.

30. M. Sagawa, K. Hiraga, H. Yamamoto, and Y. Matsuura, IEEE Trans. Magn. 20, 1584 (1984).

31. B. Gavin, Intereconomics 48, 254 (2013).

32. H. Nakamura, K. Hirota, M. Shimao, T. Minowa, and M. Honshima, IEEE Trans. Magn. 41, 3844 (2005).

33. TDK, HAL (High-Anisotropy Field Layer) Production Process (TDK Tech Journal, 2011). https://product.tdk.com/sys tem/files/dam/doc/content/archive/en/tdk_tj_hal_e_0420_2.p df. Accessed 22 July 2021.

34. T. Mishima, US2027994A (20 January 1932).

35. T. Mishima, OHM 19, 353 (1932).

36. C. Kittel, E.A. Nesbitt, and W. Shockley, Phys. Rev. 77, 839 (1950).

37. A.H. Geisler, Phys. Rev. 81, 478 (1951).

38. W.F. Brown, Rev. Mod. Phys. 17, 15 (1945).

39. A. Palasyuk, E. Blomberg, R. Prozorov, L. Yue, M.J. Kramer, R.W. McCallum, I.E. Anderson, and S. Constantinides, JOM 65, 862 (2013).

40. L. Zhou, M.K. Miller, P. Lu, L. Ke, R. Skomski, H. Dillon, Q. Xing, A. Palasyuk, M.R. McCartney, D.J. Smith, S. Constantinides, R.W. McCallum, I.E. Anderson, V. Antropov, and M.J. Kramer, Acta Mater. 74, 224 (2014).

41. L. Ke, R. Skomski, T.D. Hoffmann, L. Zhou, W. Tang, D.D. Johnson, M.J. Kramer, I.E. Anderson, and C.Z. Wang, Appl. Phys. Lett. 111, 022403 (2017).

42. Magnetic Materials Producers Association, Standard Specifications for Permanent Magnet Materials, MMPA Standard No. 0100-00 (Chicago, IL, 1990).

43. H. Zeng, R. Skomski, L. Menon, Y. Liu, S. Bandyopadhyay, and D.J. Sellmyer, Phys. Rev. B Condens. Matter. 65, 134426 (2002).

44. R.W. McCallum, L. Lewis, R. Skomski, M.J. Kramer, and I.E. Anderson, Annu. Rev. Mater. Res. 44, 451 (2014).

45. K. Binder, Rep. Prog. Phys. 50, 783 (1987).

46. I.E. Anderson, A.G. Kassen, E.M.H. White, L. Zhou, W. Tang, A. Palasyuk, K.W. Dennis, R.W. McCallum, and M.J. Kramer, J. Appl. Phys. 117, 17D138 (2015).

47. W. Tang, L. Zhou, A.G. Kassen, A. Palasyuk, E.M. White, K.W. Dennis, M.J. Kramer, R.W. McCallum, and I.E. Anderson, IEEE Trans. Magn. 51, 1 (2015).

48. E.M. White, A.G. Kassen, K.W. Dennis, A. Palasyuk, W.R. McCallum, and I.E. Anderson, Int. J. Powder Metall. 52, 33 (2016). 
49. A.G. Kassen, E.M.H. White, W. Tang, L. Hu, A. Palasyuk, L. Zhou, and I.E. Anderson, JOM 69, 1706 (2017).

50. A.G. Kassen, E.M.H. White, L. Hu, W. Tang, L. Zhou, M.J. Kramer, and I.E. Anderson, AIP Adv. 8, 056206 (2018).

51. L. Zhou, E. White, L. Ke, D.A. Cullen, P. Lu, S. Constantinides, R.W. McCallum, I.E. Anderson, and M.J. Kramer, J. Magn. Magn. Mater. 471, 142 (2019).

52. E. White, E. Rinko, T. Prost, T. Horn, C. Ledford, C. Rock, and I. Anderson, Appl. Sci. 9, 4843 (2019).

53. B. Obeid, D. Piétroy, B. Bayard, J.-P. Chatelon, S. Capraro, and J.-J. Rousseau, in $3 D$ Printed Optics and Additive Photonic Manufacturing II, edited by G. von Freymann, A. M. Herkommer, and M. Flury (SPIE-Intl Soc Optical Eng, 2020), pp. 11349T-1-11349T-11.

54. J.J. Went, G.W. Rathenau, E.W. Gorter, and G.W. van Oosterhout, Philos. Tech. Rev. 13, 194 (1952).

55. R. Valenzuela, Magnetic Ceramics (Cambridge University Press, Cambridge, 1994).

56. C.A.M. Van den Broek, and A.L. Stuijts, Philips Tech. Rev. 37, 157 (1977).

57. M.J. de Varies, 80 Years of Research at the Philips Natuurkundig Laboratorium (1914-1994) (Pallas Publicatinos, Amsterdam, 2005).

58. F.K. Lotgering, P.H.G.M. Vromans, and M.A.H. Huyberts, J. Appl. Phys. 51, 5913 (1980).

59. F. Kools, in Concise Encyclopedia of Advanced Ceramic Materials (Pergamon, 1991), pp. 200-206.

60. F. Kools, A. Morel, R. Grössinger, J.M. le Breton, and P Tenaud, J. Magn. Magn. Mater. 242-245, 1270 (2002).

61. Y. Ogata, T. Takami, and Y. Kubota, J. Jpn. Soc. Powder Powder Metall. 50, 636 (2003).

62. T. Takami, K. Yutaka, and Y. Ogata, US6858156B2 (22 February 2005).

63. S. Hosokawa, E. Oda, and H. Iwasaki, US8506838B2 (13 August 2013)
64. Y. Minachi, J. Nagaoka, N. Ito, S. Kurasawa, T. Murase, K. Takagawa, and H. Umeda, US20070009767A1 (20 July 2004).

65. A. Verma, P. Pandeyb, and P. Sharma, Indian J. Eng. Mater. Sci. 7, 364 (2000).

66. P. Reijnen, in Concise Encyclopedia of Advanced Ceramic Materials (Pergamon, 1991), pp. 445-454.

67. F.J.A. den Broeder, and P.E.C. Franken, Adv. Ceram. 1, 494 (1980).

68. J.M.D. Coey, and H. Sun, J. Magn. Magn. Mater. 87, L251 (1990).

69. H. Kato, Y. Nakagawa, N. Imaoka, and T. Fukuda, IEEE Trans. Magn. 28, 2326 (1992).

70. G. Sun and J. Chen, CN1254338C (3 May 2005).

71. K. Takagi, H. Nakayama, K. Ozaki, and K. Kobayashi, J. Magn. Magn. Mater. 324, 1337 (2012).

72. T. Saito, T. Deguchi, and H. Yamamoto, AIP Adv. 7, 056204 (2016).

73. T. Saito, M. Fukui, and H. Takeishi, Scr. Mater. 53, 1117 (2005).

74. Daido Electronics, Iostropic Polymer Bonded Sm-Fe-N Magnets (NITROQUENCH-P) (Daido Electronics 2021). $\mathrm{h}$ ttp://www.daido-electronics.co.jp/english/product/nitroquenc h_p/index.html. Accessed on 24 July 2021.

75. L. Ren, G.C. Hadjipanayis, and A. Parvizi-Majidi, J. Magn. Magn. Mater. 257, 58 (2003).

76. J.A. Horton, J.L. Wright, and J.W. Herchenroeder, IEEE Trans. Magn. 32, 4374 (1996).

Publisher's Note Springer Nature remains neutral with regard to jurisdictional claims in published maps and institutional affiliations. 